\title{
A Randomized Controlled Trial Investigating the Effects of Undulatory, Staggered, and Linear Load Manipulations in Aerobic Training on Oxygen Supply, Muscle Injury, and Metabolism in Male Recreational Runners
}

Paulo Costa ${ }^{1,2^{*}}$, Roberto Simão ${ }^{1}$, Anselmo Perez ${ }^{3}$, Maurício Gama ${ }^{1}$, Rogério Lanchtermacher ${ }^{1}$, Reinaldo Musialowski ${ }^{1}$, Fábio Braga', Valeria de Mello Coelho ${ }^{2}$ and Alexandre Palma ${ }^{1 *}$

\begin{abstract}
Background: Taper is considered as a strategy to avoid overtraining and increase peak performance in athletes. Because aerobic exercise increases the level and duration of independence during the lifespan, the participation of recreational athletes has increased in running events around the world. However, the effects of using load reduction in their training and aerobic performance are still not well known.
\end{abstract}

Objectives: Our goal was to compare load manipulations, using tapering-like periods in the end of recreational athletes training evaluating alterations in oxygen supply, muscle injury, and metabolism markers.

Methods: Healthy males ( $n=88,20-35$ years old) were randomly distributed in groups using a combination of two mesocycles of 4 weeks, undulatory and staggered, with two daily microcycles, undulatory and linear. Undulatoryundulatory (Und-Und) and undulatory-linear (Und-Lin) groups had load reduction in the final week of training while the staggered-undulatory (Sta-Und) and staggered-linear (Sta-Lin) groups did not. Cardiorespiratory capacity $\left(\dot{V}_{2}{ }_{2 m a x}\right)$, body mass index (BMI), and body fat \% were evaluated. Blood samples were also collected to analyze hematocrit $(\mathrm{Ht})$, mean corpuscular hemoglobin $(\mathrm{MCHC})$, circulating levels of hemoglobin $(\mathrm{Hb})$, creatine kinase $(\mathrm{CK})$, lactate dehydrogenase (LDH), aspartate aminotransferase (AST), alanine aminotransferase (ALT), urea (U), cortisol (C), free testosterone (FT), and free $\mathrm{T} / \mathrm{C}$ ratio.

Results: After 8 weeks of training, Und-Und had the highest trend to increase $\mathrm{V}_{2 \text { max }}$. Both Und-Und and Sta-Lin reduced body fat \%. Und-Und showed a significant increase in MCHC, T and Free T/C ratio, a positive trend to increase $\mathrm{Ht} \%$ and $\mathrm{Hb}$ levels, and a trend to decrease $\mathrm{CK}, \mathrm{LDH}$, and C circulating levels. Sta-Lin presented a trend to decrease $\mathrm{Ht} \%$ and $\mathrm{Hb}$ levels, a significant increase in CK, LDH, AST, ALT circulating levels, and a decrease in Free T/C ratio.

Conclusion: The use of daily undulatory training load provides better gains for aerobic fitness while the use of staggered load, mainly associated with linear load, promotes inadequate recovery in recreational runners.

Keywords: Aerobic training, Taper, load manipulation, aerobic fitness, Oxygen supply, Muscle injury

\footnotetext{
* Correspondence: paulocostancf@gmail.com;

palma_alexandre@yahoo.com.br

${ }^{1}$ School of Physical Education and Sports, Rio de Janeiro Federal University,

Av. Carlos Chagas Filho, 540 - Cidade Universitária, Rio de Janeiro, RJ

21940-901, Brazil

Full list of author information is available at the end of the article
} 


\section{Key Points}

- The use of taper-like periods after undulatory training volume loads can contribute to increase cardiorespiratory fitness and to benefit recovery while linear loads promote inadequate recovery in recreational runners.

- Recreational runners that perform undulatory cycles weekly and monthly with a decrease in volumes after 4 weeks of training increase their cardiorespiratory fitness and free testosterone/cortisol ratio and decrease the circulating levels of muscle injury markers after 8 weeks of training.

- Recreational runners that perform weekly linear loads and monthly staggered loads, without a taper-like period after the training, increase serum markers of protein catabolism and muscle injury and decrease free testosterone/cortisol ratio, indicating inefficient recovery after eight weeks of training.

\section{Background}

Intensive exercise or inadequate recovery causes overtraining, which correspond to a state of prolonged fatigue and consequently decreased physical performance [1-4]. Overtraining promotes several psychological symptoms such as fear of competition, general apathy, emotional stress, and depression $[5,6]$, which can lead to higher susceptibility to immunodeficiency and infections $[1,5]$. Moreover, overtraining causes physiological alterations including reduction of muscle glycogen [7] and in the circulating levels of catecholamines [2], lactate $[2,8]$, and free testosterone (FT) $[1,2,9,10]$. On the other hand, it increases the circulating levels of urea $(\mathrm{U})[2,9,10]$, creatine kinase $(\mathrm{CK})[4$, 11], oxidative enzymes [12], and cortisol (C) [2, 9, 11, 13]. Excepting one study showing a decrease in the levels of lactate dehydrogenase (LDH) [14], other groups have shown an increase in the levels of this enzyme, when taper was used $[8,15]$. Overtraining leads to endocrine disorders such as a decrease of more than $30 \%$ in the FT/C ratio [2, $10,16]$. Initially, the increased levels of cortisol could compromise training adaptation because it contributes to decrease glycogen reserve and neuromuscular activity [17]. It is also described that short-endurance exercise, chronic fatigue, and insufficient recovery modulate hypothalamic-pituitary-adrenal axis increasing adrenocorticotrophic hormone/cortisol ratio due to decreased sensitivity of the pituitary [18]. The adaptive response to the HPA imbalance can promote a reduction in the cortisol activity thus regulating metabolic actions, increasing gluconeogenesis, or central action, altering adrenoreceptors sensitivity influencing on analgesia, for instance $[18,19]$. In overtraining, an efficient strategy to optimize the performance avoiding or reversing the deleterious effects and alteration in the neuroendocrine system is to promote supercompensation through adequate recovery $[20,21]$. In this regard, the law of overcompensation refers to adequate recovery after various training loads and/or a training session in order to achieve better skill levels [22, 23]. High-level athletes always possess the characteristic of accumulations of training hours that involve the manipulation of volume, intensity, frequency, duration of the session, and type of exercise. In this way, recovery from accumulation of training loads becomes necessary to obtain positive effects. Several studies show that reduction of aerobic training loads prior to competition, also known as taper, has been considered by coaches to avoid detraining [24-28], overtraining [25, 29, 30], and to optimize performance of athletes [2, 9, 28-30]. Indeed, taper is a common strategy among competitive athletes to ensure proper recovery $[28,31,32]$.

During the reduction of aerobic training, several variables can be manipulated and even combined in an attempt to maximize performance. Some of these variables include the weekly reductions in frequency, volume, intensity, duration, and type of taper [33-37]. Models of taper include step, exponential with low or high decay, linear $[25,31]$, or through phases $[35,36]$. Significant improvements have also been reported using undulatory and nonundulatory models of low training loads in runners [32, 33], swimmers [37, 38], cyclists [39, 40], and triathletes [5]. In this context, the application of training workload manipulation promotes a balance among distinct training loads and recovery periods, thus decreasing the chances of low performance due to injury, detraining, and overtraining $[41,42]$. In relation to the use of aerobic training load reduction prior to competition, nine middle-distance runners were evaluated, being five submitted to high frequency taper and four to moderate frequency taper. Athletes showed an improvement in their performance during a 6-day taper. However, when runners rested every third day of the training, no significant gain was observed. The authors also tested levels of testosterone and cortisol and observed that hormonal levels propitious to anabolic processes were associated with an optimum performance [32]. Another group evaluated individually long-term training of 11 elite skiers and biathletes that had exceptional performances [43]. They also used a taper strategy. However, only three of 11 athletes had a resting day in the five final days prior to the peak performance while the majority of the elite athletes had rest days from training in the middle period of the peaking phase between the final 12 to 6 days prior the peak performance. Authors did not analyze markers for muscle injury or metabolic markers, such as testosterone and cortisol to correlate the athletes' performance with their physiological conditions [43].

Regular physical exercise and fitness have been associated with reduction of mortality and improvement of health [44]. Aspects of health-related physical fitness include cardiorespiratory fitness, muscular strength, muscular endurance, body composition, and flexibility [45]. 
In this context, participation of recreational runners, also known as amateurs runners, has increased in running events around the world, including those of 5 or $10 \mathrm{~km}$ races, half-marathons, and marathons [45, 46]. Recreational runners have shown interest in training programs aiming their success to complete the running or to improve their run time. In this regard, inappropriate training can contribute for muscle stress and lesions or overtraining [46-48]. For this reason, studies of intensity manipulation have been performed also with recreational runners [49-51]. Models of load reduction in recreational athletes have also been proposed in runners [51-54] in order to observe hemodynamic variables and cardiorespiratory fitness. The use of taper in the training of recreational runners has been investigated and considered positive to improve physical adaptation [51]. In another study, sedentary individuals-who had not performed regular aerobic exercises during a previous year-were recruited, and entered into a 5-month training program, four to six times a week, with a $75 \%$ intensity of maximal oxygen uptake $\left(\dot{\mathrm{V}}_{2 \max }\right)$ [55]. Other group also showed that sedentary individuals participated in a training program (30 min daily, 5 days/week) for 12 weeks to assess cardiorespiratory fitness [56]. In the current study, we considered the use of taper-like models as a possible strategy to optimize the cardiorespiratory fitness of recreational athletes in running events, based on several studies that show positive results of using taper in training of athletes $[3,25$, 30-32, 34-36, 39].

Using a novel model of analysis, where tapering and distinct periodization were applied in the training program of recreational athletes submitted to aerobic exercise, we have shown that loading manipulation can ameliorate their aerobic fitness [57]. However, the physiological alterations in recreational athletes submitted to aerobic training programs with distinct load manipulation as well as reduction in the final period of exercise (taper-like period) are still unknown. In this study, we analyzed the cardiorespiratory capacity $\left(\dot{\mathrm{V}}_{2 \max }\right)$ of recreational before and after 8 weeks of running, comparing the training effects with undulatory and/or non-undulatory load manipulations. We also evaluated the circulating levels of hematological, biochemical, and hormonal markers before, during, and after the aerobic training.

\section{Methods}

\section{Subjects}

The study recruited 97 individuals. However, 93 participants started training and 88 completed. All volunteers were informed verbally and in writing regarding the purpose, procedures, and potential risks of the study, according to the Helsinki declaration. Each participant provided written informed consent to be part in the study reviewed and approved under the protocol number $024 / 10$ by the local Committee on Human Research in the University Hospital Clementino Fraga Filho at Federal University of Rio de Janeiro.

\section{Research Design}

The inclusion criteria adopted in this study were males, in the age of 20 to 35 years; that frequently run at least twice a week, lasting between 30 and 120 min per day for at least 6 months; and agreed to not participate in any additional exercise during the study period. All participants were physically active and did not take part in any form of organized competitive athletics. The exclusion criteria included medical condition that could endanger their health, such as hypertension or cardiac abnormalities; tobacco use; functional limitations that could compromise their exercise capacity, such as orthopedic and neurological disorders; use of medication, either for treatment of an illness or ergogenic effect; positive response to the PAR-Q questionnaire; $\dot{\mathrm{VO}}_{2 \max }$ lower than $33 \mathrm{ml} \mathrm{kg}^{-1} \mathrm{~min}^{-1}$; and body fat percentage greater than $25 \%$. We should point out evidences linking low levels of cardiorespiratory fitness with increased cardiovascular mortality considering that the relative risk of death may be related to a lower functional capacity independently of the risk factors involved [58-62]. In this regard, $\dot{\mathrm{VO}}_{2 \max }$ below $33 \mathrm{ml} / \mathrm{kg} / \mathrm{min}$ has been classified as "Weak" [63] or "very poor" [64], and body fat $\% \geq 25 \%$ was considered "weak" or "poor" and associated with cardiovascular risk $[64,65]$. Diet was not prescribed but participants were recommended to eat healthy.

All participants answered a questionnaire that allowed verifying their usual training frequency ( 2 to 6 days per week, being $15.91 \%, 2$ days; $37.51 \%$, 3 days; $22.72 \%$, 4 days; $18.18 \%, 5$ days and $5.68 \%$ that run 6 days per week), weekly volume (14.4 to $55 \mathrm{~km})$, and intensity (6.9 to $10 \mathrm{~km} / \mathrm{h}$ ). Participants were then submitted to anthropometric measurements, blood collection, and cardiorespiratory physical fitness in the pre-training period (Fig. 1). In these groups, the weekly mesocycle, which consists of 4 weeks, was manipulated in two ways, called "undulatory" and "staggered", as previously described [57]. The daily microcycle (from Monday to Friday) was established also in two ways, called "undulatory" and "linear" [57]. All experimental groups performed the same overall training load, although the loads were distributed differently. The participants, randomly assigned into four groups, performed 8 weeks of aerobic training (Fig. 2). Two groups of trainings that used taper-like periods, undulatory-undulatory (Und-Und) $(n=18)$ and undulatory-linear (Und-Lin) $(n=19)$, had load reduction at two moments: after 4 and 8 weeks of training. The two other groups, staggered-undulatory (Sta-Und) $(n=$ $17)$ and staggered-linear (Sta-Lin) $(n=18)$, did not used taper-like periods; there was first an increase in the load 


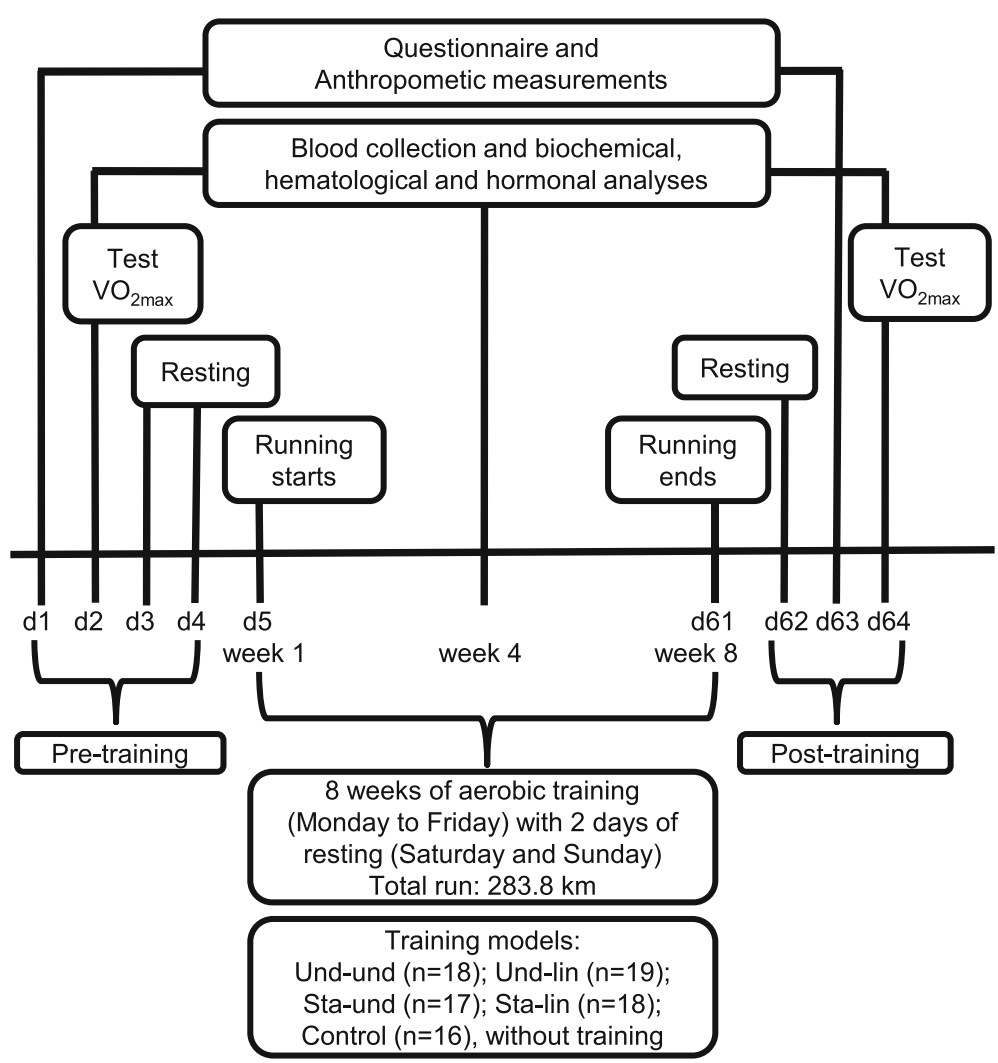

Fig. 1 Experimental design of the study. Healthy males ( $n=88,20-35$ years old) were submitted to physical and physiological evaluation before (pretraining), during (aerobic training), and after 8 weeks of aerobic training (post-training), as indicated. The participants performed 8 weeks of aerobic training randomly assigned into four groups based on distinct periodization models: undulatory-undulatory (Und-Und); undulatory-linear (Und-Lin); staggered-undulatory (Sta-Und); staggered-linear (Sta-Lin). Each training participant ran a total of $283.8 \mathrm{~km}$ throughout the distinct trainings. Control group maintained their usual aerobic training twice a week

and no load reduction in the final week of training. The participants in these groups did not reach their final stage since they were monitored to maintain $70 \%$ of their $\dot{\mathrm{V}} \mathrm{O}_{2 \max }$ during the aerobic training. The control group included participants that usually train at least 2 days a week and maintained their usual routine during the 8 weeks of aerobic training period of the study $(n=$ 16). Each training group performed continuous running 5 days/week, and had three physical education professionals monitoring and controlling the training load.

The aerobic training was performed between the months of September and November, spring season in Rio de Janeiro. For 8 weeks, 5 days per week, participants started training around 8:00 am on a $400 \mathrm{~m}$ official track of athletics (outdoors), with markings every $10 \mathrm{~m}$. Each participant received a digital clock with a stopwatch in order to control their own time and pace. In addition, two researchers were positioned in the markings $200 \mathrm{~m}$ and $400 \mathrm{~m}$ to supervise the pace of the runners. The intensity for every participant was determined by their $\dot{\mathrm{V}}_{2 \max }$ of $70 \%$ and controlled by the speed of the running (range 3 to $10.6 \mathrm{~km}$ per session; 26.07 to $91.62 \mathrm{~min} / \mathrm{session}$ ), with a weekly volume between
30.1 and $43 \mathrm{~km}$ and total volume (100\%) of $283.3 \mathrm{~km}$, at the end of 8 weeks, which in average corresponded to $7.095 \mathrm{~km} /$ day. Each participant received the distance and total execution time daily, based on their $\dot{\mathrm{VO}}_{2 \max }$. Studies have reported the use of \% of $\mathrm{VO}_{2 \max }$ as a parameter for the prescription of exercise intensity in order to improve cardiorespiratory fitness [66-69].

The randomized distribution of volunteers in the different groups was done according to their $\dot{\mathrm{VO}}_{2 \max }$. The $\dot{\mathrm{V}} \mathrm{O}_{2 \max }$ test was measured by one of the authors of the study. Another author made the ranking decreasing the $\dot{\mathrm{V}} \mathrm{O}_{2 \max }$ values and distributing volunteers in each groups. For instance, higher value of $\dot{\mathrm{VO}}_{2 \max }$ : Und-Und group; second higher value: Und-Lin group; third higher value: StaUnd group; fourth higher value: Sta-Lin group; fifth higher value: Und-Lin group; sixth higher value: Sta-Und group; seventh higher value: Sta-Lin group; eighth higher value: Und-Und group. The Kolmogorov-Smirnov test was performed to verify the normality of the groups.

We considered 5-day running per week in this study design, based on physical activities guidelines from the American College of Sports Medicine [64] that 

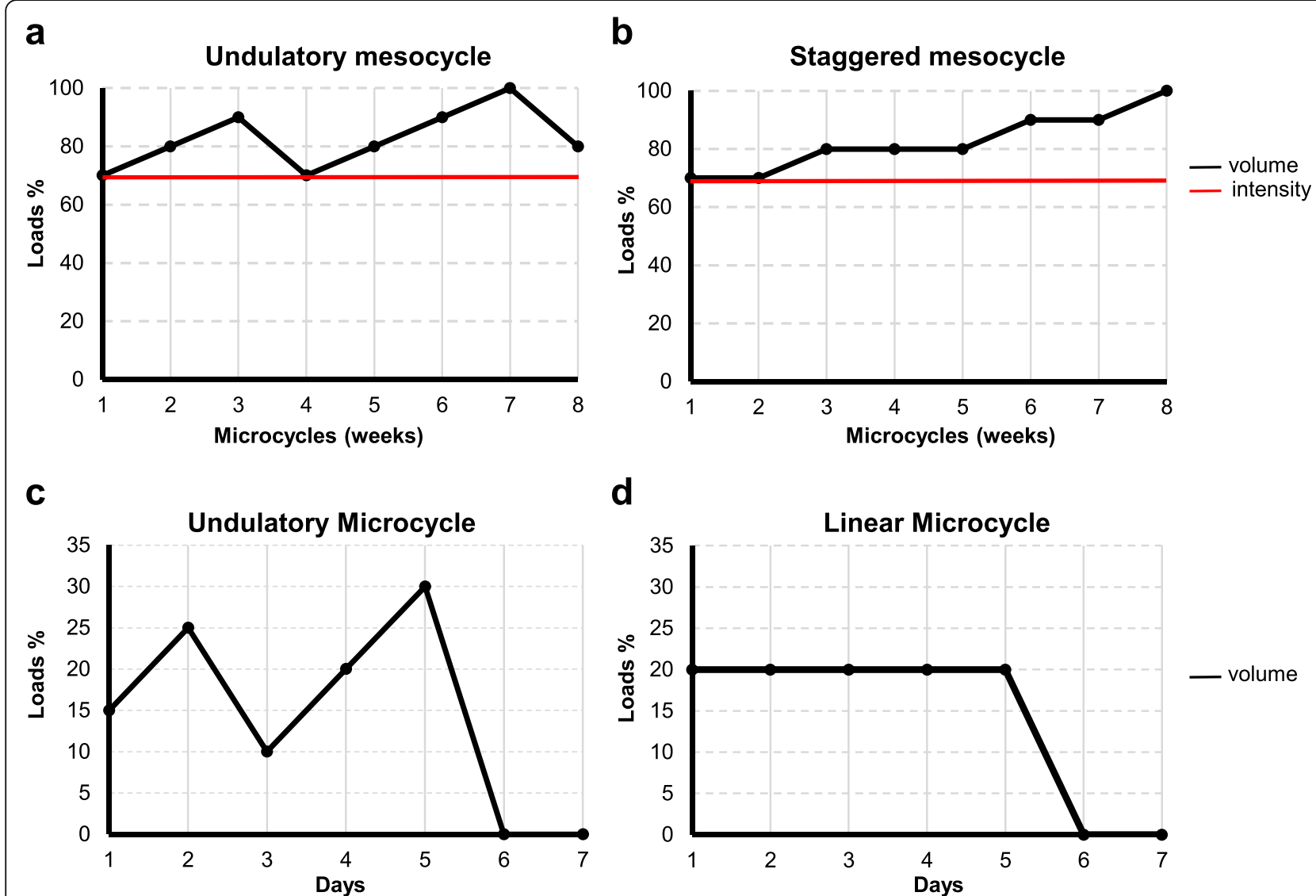

Fig. 2 Load manipulation models applied to recreational athletes aerobic trainings. Participants were randomly distributed in training groups using a combination of two mesocycles of 4 weeks, a undulatory and $\mathbf{b}$ staggered, with two daily microcycles, $\mathbf{c}$ undulatory and $\mathbf{d}$ linear. Training intensity was maintained at $70 \%$ of $\dot{V}_{2 \max }$ through changes in running speed. Each training group performed continuous running 5 days/week. Training intensity (\% of $\dot{\mathrm{V}} \mathrm{O}_{2 \max }=70$ ) and volume (\% of the maximum distance run/per week) are indicated in the graphs. Adapted from [5]

recommend healthy adults to practice cardiorespiratory training of moderate intensity between 30 and $60 \mathrm{~min} /$ day, $\geq 150 \mathrm{~min} /$ week in 5 days/week [45, 70, 71].

\section{Anthropometric Measurements}

All participants were weighed by a mechanical scale (Filizola', model 31, Brazil) with a capacity of $150 \mathrm{~kg}$ and precision of 50 g. ASIMED ${ }^{\circ}$ Stadiometers (Spain), which presents a scale in millimeters used in order to obtain the participants' height. The body mass index (BMI) was obtained by dividing weight $(\mathrm{kg})$ per height $\left(\mathrm{m}^{2}\right)$ (Quetelet's equation). Body fat percentage (body fat \%) was estimated from the measurement of skinfolds (triceps, subscapular, suprailiac, chest, abdominal, medium underarm, and thigh) using a Lange $e^{\circ}$ compass, with an accuracy of $0.1 \mathrm{~mm}$ and predictive equations [72]. The equation developed by Jackson and Pollock [73] was used to calculate body density. Each skinfold was measured three times in a circuit, with the average of the three results considered as final index. The anthropometrical data collection before and after 8 weeks was conducted at the Exercise Physiology
Laboratory (LaboFisE) of the Federal University of Rio de Janeiro, by a technician specialized in biometry and performed by the same evaluator with 7 years of experience in anthropometric analysis. The technical measurement error (ETM) that is, the variation in two different instants, was acceptable (ETM-relative: $2.1 \%$ ).

\section{Cardiorespiratory Physical Fitness Test}

The participants performed a cardiopulmonary exercise test with direct oxygen measurement (ergospirometry) on a treadmill (ECAFIX-EG700.2-Brazil). The flow measurement was obtained from the pneumotachograph (MEDGRAF) and the analysis of exhaled gas was performed using $\mathrm{VO}_{2000}$ (Inbrasport-Brazil). The following ventilatory variables were analyzed: minute ventilation (VE, $1 \mathrm{~min}^{-1}-$ BTPS) and maximal oxygen uptake $\left(\dot{\mathrm{V}}_{2 \max }, 1 \mathrm{~min}^{-1}\right.$ STPD). Values of oxygen $\left(\mathrm{FO}_{2}\right)$ and carbon dioxide $\left(\mathrm{FCO}_{2}\right)$ were verified through calibration before and after the tests to correct possible deviations after exercise [74]. The calibration of the gas analyzer was performed by the device itself within $1 \mathrm{~h}$ prior to the start of the first evaluation, 
following the manufacturer's recommendations (Pneumotachograph CPX, Medical Graphics Corp., St. Paul, MN). The gaseous samples were collected and measured every $10 \mathrm{~s}$ during the test.

All tests were performed under similar temperature conditions $\left(22^{\circ} \mathrm{C}\right.$ and $24{ }^{\circ} \mathrm{C}$ ), relative air humidity (between 40 and $60 \%$ ), and barometric pressure of $760 \mathrm{mmHg}$. The day before the $\dot{\mathrm{VO}}_{2 \max }$ analysis, participants were asked to avoid any strenuous exercise. Blood pressure (BP) was measured using the auscultatory method and heart rate $(\mathrm{HR})$ was measured using electrodes (Micromed) placed at the manubrium and in the left and right iliac crest (derivation CM5), while participants were on the treadmill. The electrodes were connected to an electrocardiograph (Micromed) and HR values were visualized using the Elite software (Micromed Biotechnology, Brazil). The criteria used to find maximum oxygen consumption $\left(\dot{\mathrm{V}} \mathrm{O}_{2 \max }\right)$ were a minimum of two of the following: (a) establishment of the oxygen uptake curve plateau relative to the load; (b) gas exchange ratio $\geq$ 1.1 [75]; (c) score $\geq 17$ from 6 to 20 Borg's scale [75]; and (d) maximum heart rate predicted for [208 - $(0.7 \times$ age $)]$ [76]. The modified Bruce protocol was utilized for the cardiovascular testing [77]. This protocol includes 3-min stages with progressive loads determined by the increase in speed and incline, being $5 \mathrm{~min}$ of activity $(1.60 \mathrm{mph})$ at $0 \%$ incline (warm up). The test was run from the first stage: $3 \mathrm{~min}$, speed $=1.7 \mathrm{mph}$, slope $=0 \%$; second stage: $3 \mathrm{~min}$, speed $=2.5 \mathrm{mph}$, slope $=12 \%$; third stage: $3 \mathrm{~min}$, speed $=$ $3.4 \mathrm{mph}$, slope $=14 \%$; fourth stage: $3 \mathrm{~min}$, speed $=$ $4.2 \mathrm{mph}$, slope $=16 \%$; fifth stage: $3 \mathrm{~min}$, speed $=5.0 \mathrm{mph}$, slope $=18 \%$; sixth stage: $3 \mathrm{~min}$, speed $=5.5 \mathrm{mph}$, slope $=$ $20 \%$; seventh stage: $3 \mathrm{~min}$, speed $=6.0 \mathrm{mph}$, slope $=22 \%$.

\section{Blood Samples}

Blood samples were obtained three times during the study: at baseline (pre-training), after 4 weeks, and after 8 weeks of training (post-training) in the beginning of the microcycle or $72 \mathrm{~h}$ after ending the 8th microcycle. Blood samples were collected at 8:00 am after $12 \mathrm{~h}$ of fasting. Three samples of $15 \mathrm{ml}$ of blood were collected from the cephalic vein located in the antecubital fossa, and placed in tubes containing ethylenediaminetetraacetic acid (EDTA) without an anticoagulant for hematologic, biochemical, and hormonal analyses. Blood samples were maintained at $-2{ }^{\circ} \mathrm{C}$ to $-8{ }^{\circ} \mathrm{C}$ until the serum was separated by direct centrifugation at $3000 \mathrm{rpm}$ for $15 \mathrm{~min}$ (Centra-8R IEC, MA). Serum samples were kept on ice and taken to freezer at $-20{ }^{\circ} \mathrm{C}$ until the time of analysis. The collection, storage, processing, and analysis of blood samples were performed by a specialized team consisting of a doctor and a nurse, both with experience in biochemical-hematological and hormonal tests.

\section{Blood Analysis}

Serum levels of CK, LDH, U, aspartate aminotransferase (AST), and alanine aminotransferase (ALT) were performed by enzymatic methods using a Targa bt $3000^{\circ}$ biochemical autoanalyzer. The biochemical reagents used were of the brand Wienner lab ${ }^{\bullet}$ (Wiener Lab, Rosario, Argentina). Concentrations of hemoglobin $(\mathrm{Hb})$ and hematocrit $(\mathrm{Ht})$ were measured by the spectrophotometric method using Cell-Dyn 3500 (System Operators Manual, Abbott Laboratories, Abbott Park, Illinois, USA). Mean corpuscular hemoglobin concentration $(\mathrm{MCHC})$ was also calculated. Quantification of FT and cortisol (C) in the serum were done using kits (Elecsys 2010, Roche diagnostics, Germany) and analyzed by electrochemiluminescence and chemiluminescence, respectively, using an Hitachi Modular equipment (Hitachi, Tokyo, Japan). All analyses followed the protocol of their manufacturers and were performed in duplicates. Between and within coefficients of variation for all assays were less than $10 \%$ for all biochemical analyses.

\section{Statistical Analysis}

The Kolmogorov-Smirnov test was used to check the normality of sample distribution and examined the appropriateness of using parametric tests. Analysis of variance (ANOVA) (mixed-design) was used to compare the differences between the "pre-training," "after 4 weeks," and "post-training" mean in the same group and between groups Und-Und, Und-Lin, Sta-Und, Sta-Lin versus control. Comparisons between the means of each variable studied, in the five groups were performed using ANOVA followed by the Tukey post-hoc test in order to identify the location of the differences in the dependent variables. Intra-class correlation coefficients (ICCs) were used to determine test-retest reliability. For the "pretraining" variables, effect size was calculated using Cohen's d equation by subtracting the means of "posttraining" and "pre-training" and dividing by the pooled "post-training" and "pre-training" standard deviations. The ranges adopted for small, medium, and large effects were $0.20,0.50$, and 0.80 , respectively [78].

\section{Results}

\section{Analyses of $\dot{\mathrm{V}}_{2 \max }$}

In our study, we considered running as choice to evaluate cardiorespiratory capacity of the participants that were distributed in four different training groups and the control group based on Latin square design. In this context, the participants were distributed from the one with higher $\dot{\mathrm{V}}_{2 \max }$ to the one with lower $\dot{\mathrm{V}} \mathrm{O}_{2 \max }$ in the following sequence: Und-Und; Und-Lin; Sta-Und; StaLin; and the control group. We did not find significant differences among the training groups and the control before $(p=0.95)$ and after 8 weeks of exercise $(p=0.71)$ 
(Fig. 3). In addition, no changes were observed in the cardiorespiratory fitness of the control group between pre-training and post- 8 weeks of training $(41.0 \pm 3.5$ versus $41.1 \pm 6.9$, respectively) (Fig. 3). However, evaluating the participants before and after training, we verified a trend to increase the mean values of the $\dot{\mathrm{VO}}_{2 \max }$ in all training groups: Und-Und, $37.9 \pm 8.5$ versus $46.3 \pm 6.2$; Und-Lin, $38.9 \pm 8.5$ versus $45.2 \pm 5.12$; Sta-Und, $41.3 \pm$ 8.8 versus $46.1 \pm 6.22$; Sta-Lin $38.6 \pm 10.3$ versus $42.9 \pm$ 8.1 , respectively comparing before and after 8 weeks of training (Fig. 3). No statistically significant differences were observed among the different training groups. The percentage changes and effect size calculations demonstrate that Und-Und group had the higher increase in $\dot{\mathrm{V}} \mathrm{O}_{2 \max }(\Delta \%=22.15 \%, d=1.14, p=0.01)$ followed by Und-Lin ( $\Delta \%=16.01, d=0.85, p=0.02)$, Sta-Und $(\Delta \%=$ 11.47, $d=0.63, p=0.02)$, and Sta-Lin groups $(\Delta \%=$ 11.16, $d=0.49, p=0.04$ ) (Fig. 3).

\section{Circulating Levels of Hemoglobin and Hematocrit \%}

Our data showed no significant changes in $\mathrm{Ht} \%$ among the distinct groups after 4 and 8 weeks of aerobic training (Fig. 4). However, we verified a positive trend to increase $\mathrm{Ht} \%$ in the Und-Und group, in relation to the other models, 8 weeks post-training (Und-Und: $42.2 \pm 3.1$ versus $44.7 \pm 2.2, \Delta \%=5.93, d=0.96, p=0.24$; Und-Lin: $41.2 \pm 5.3$ versus $42.7 \pm 1.2, \Delta \%=3.64, d=0.46, p=0.56$; Sta-Und: $44.0 \pm 1.2$ versus $44.4 \pm 2.61, \Delta \%=0.91, d=0.21, p=0.76$; Sta-Lin: $44.7 \pm 3.0$ versus $43.7 \pm 2.0, \Delta \%=-2,24, d=0.40$, $p=0.42$; and control group $41.7 \pm 3.8$ versus $42.7 \pm 2.7$, $\Delta \%=2,40, d=0.31, p=0.35$ ) (Fig. 4a). In relation to the plasma levels of $\mathrm{Hb}$, no significant alteration was verified when comparing the distinct groups of load manipulation with the control after 4 weeks of training (Fig. 4b).
However, after 8 weeks of training, $\mathrm{Hb}$ levels showed a trend to increase in proportion in the Und-Und group in comparison with the other training groups: Und-Und: $13.9 \pm 1.2$ versus $15.0 \pm 0.8, \Delta \%=8.16, d=1.10, p=0.19$; Und-Lin: $15.0 \pm 0.9$ versus $16.2 \pm 0.9, \Delta \%=7.86, d=1.26$, $p=0.01$; Sta-Und: $15.4 \pm 0.6$ versus $16.5 \pm 1.1, \Delta \%=7.15$, $d=1.33, \quad p=0.04 ;$ Sta-Lin: $15.7 \pm 1.0$ versus $15.6 \pm 0.7$, $\Delta \%=-0.46, d=0.09, p=0.81 ;$ and control group $14.4 \pm 1.3$ versus $15.2 \pm 0.7, \Delta \%=5.20, d=0.75, p=0.16$. After 8 weeks of training, Sta-Und model showed a lower gain in $\mathrm{Ht}$ and a trend to increase $\mathrm{Hb}$ levels while Sta-Lin group showed a trend to decrease $\mathrm{Ht} \%$ and $\mathrm{Hb}$ levels. On the other hand, Und-Und group showed a trend to increase $\mathrm{Ht} \%$ and $\mathrm{Hb}$ levels. Evaluating the $\mathrm{MCHC}$, only Und-Und showed a significant increase in comparison with the control group, 8 weeks post aerobic training (Fig. 4c): Und-Und: $34.1 \pm 1.3$ versus $40.2 \pm 2.3, \Delta \%=19.41, d=1.12, p=0.04$; Und-Lin: $37.3 \pm 5.0$ versus $39.2 \pm 3.1, \Delta \%=4.69, d=0.34, p=0.38$; Sta-Und: $36.2 \pm 1.5$ versus $38.4 \pm 4.1, \Delta \%=4.16, d=0.30$, $p=0.55$; Sta-Lin: $35.0 \pm 0.9$ versus $39.0 \pm 1.8, \Delta \%=8.51$, $d=0.40, p=0.09$; and control group $35.2 \pm 1.4$ versus $38.0 \pm 2.8, \Delta \%=7.99, d=1.03, p=0.06$. We did not find significant difference in intergroups. These data suggest that the Und-Und load manipulation model was the one that most contributed for oxygen supply in recreational athletes.

\section{Body Mass Index and Body Fat \%}

As shown in Table 1, our analyses indicate that the BMI mean in all groups in the pre-training phase, before the aerobic training, varied from 25.1 to $26.0 \mathrm{~kg} / \mathrm{m}^{2}$ being not statistically different among groups $(p=0.99)$. Moreover, we verified that after 8 weeks of training, the BMI values of Und-Und, Und-Lin, Sta-Und, and Sta-Lin groups and the control varied from 24.8 to $26.2 \mathrm{~kg} / \mathrm{m}^{2}$

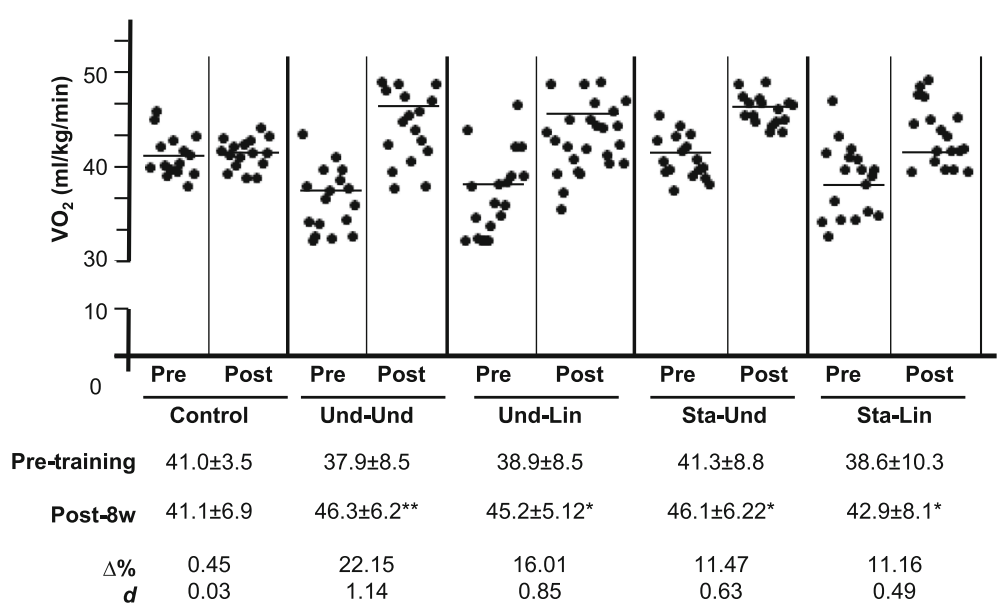

Fig. 3 Effects of distinct aerobic trainings and taper-like periods on cardiorespiratory capacity of recreational athletes. Mean values of maximum oxygen consumption $\left(\mathrm{V}_{2 \text { max }}\right.$ ) of healthy males before (pre) and after 8 weeks (post) of aerobic training. Groups: control (without training); undulatory-undulatory (Und-Und); undulatory-linear (Und-Lin); staggered-undulatory (Sta-Und); staggered-linear (Sta-Lin). Each black circle represents a participant in each group. Below graphs, the respective mean \pm standard deviation values. ${ }^{*} p \leq 0.05 . \Delta$, variation; $d$, effect size 
a

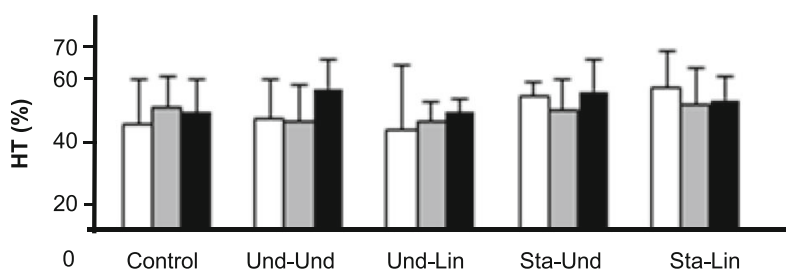

$\begin{array}{ccccccc}\text { Post } & \Delta \% & 3.59 & -0.40 & 2.02 & -2.27 & -2.88 \\ \text { 4-w } & \boldsymbol{d} & 0.48 & 0.05 & 0.24 & 0.56 & 0.44 \\ & \boldsymbol{p} & 0.18 & 0.82 & 0.64 & 0.41 & 0.23 \\ \text { Post } & \Delta \% & 2.40 & 5.93 & 3.64 & 0.91 & -2.24 \\ \text { 8-w } & \boldsymbol{d} & 0.31 & 0.96 & 0.46 & 0.21 & 0.40 \\ & \boldsymbol{p} & 0.35 & 0.24 & 0.56 & 0.76 & 0.42\end{array}$

b
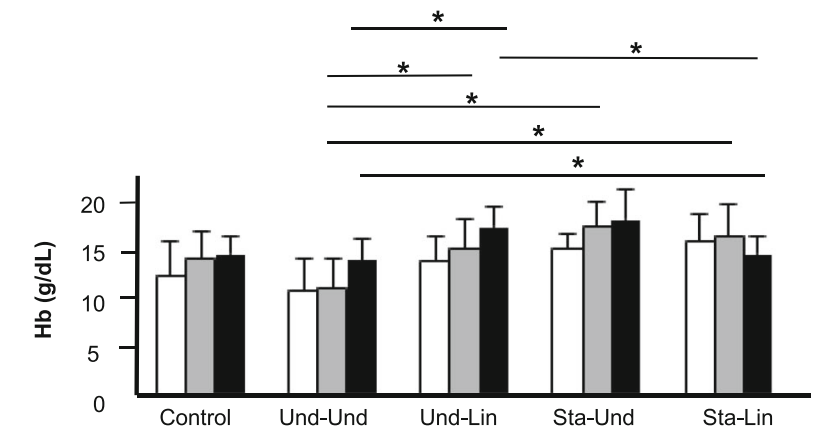

$\begin{array}{ccccccc}\text { Post } & \Delta \% & 4.51 & 1.20 & 2.21 & 5.33 & 0.27 \\ \text { 4-w } & \boldsymbol{d} & 0.56 & 0.14 & 0.36 & 1.05 & 0.04 \\ & \boldsymbol{p} & 0.26 & 0.57 & 0.10 & 0.08 & 0.89 \\ & & & & & & \\ \text { Post } & \Delta \% & 5.20 & 8.16 & 7.96 & 7.15 & -0.46 \\ \text { 8-w } & \boldsymbol{d} & 0.75 & 1.10 & 1.26 & 1.33 & 0.09 \\ & \boldsymbol{p} & 0.16 & 0.19 & 0.01^{*} & 0.04^{*} & 0.81\end{array}$

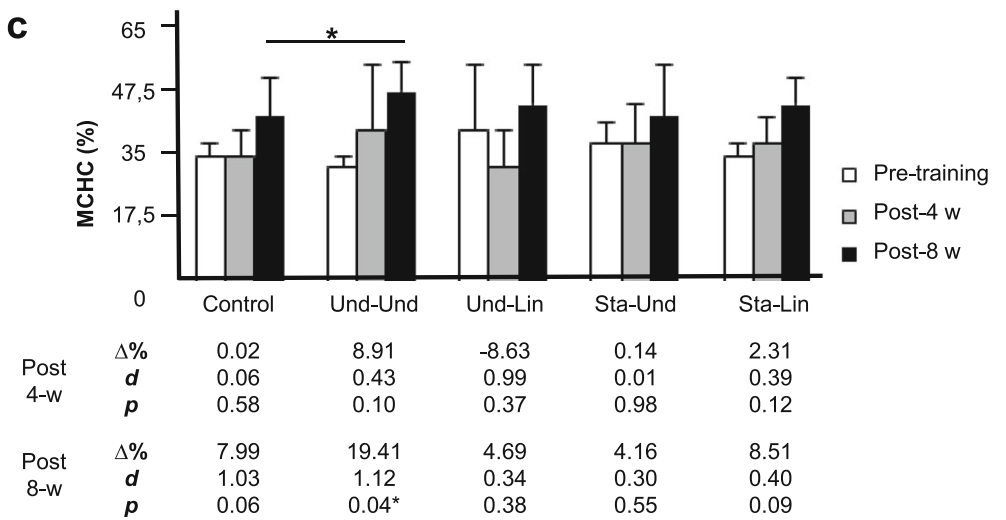

Fig. 4 Effects of distinct aerobic trainings and taper-like periods on markers of $\mathrm{O}_{2}$ transport capacity to tissues in recreational athletes. Mean \pm standard deviation values of $\mathbf{a}$ hematocrit \%, $\mathbf{b}$ circulating levels of hemoglobin (HB), and $\mathbf{c}$ mean corpuscular hemoglobin concentration (MCHC) of recreational athletes before (white bar), post 4 (gray bar, 4-w) or 8 weeks (black bar, 8-w) of distinct aerobic trainings. Groups: control (without training), undulatoryundulatory (Und-Und), undulatory-linear (Und-Lin), staggered-undulatory (Sta-Und), and staggered-linear (Sta-Lin). $\Delta$, variation; $d$, effect size; *indicates $p \leq 0.05$. Statistical bars indicate comparisons between distinct groups

$(p=0.98)$. We found the following BMI mean values for each group: Und-Und, $25.8 \pm 4.6$ versus $24.9 \pm 4.4, \Delta \%=$ $-8.70, d=0.05$; Und-Lin, $25.8 \pm 5.2$ versus $25.7 \pm 5.3$, $\Delta \%=-0.32, d=0.02$; Sta-Und, $25.1 \pm 3.0$ versus $24.8 \pm$ 3.0, $\Delta \%=-0.87, d=0.10 ;$ Sta-Lin $25.9 \pm 4.6$ versus $25.8 \pm 4.4, \Delta \%=-0.12, d=0.02$; and control group:
$26.0 \pm 0.4$ versus $26.2 \pm 0.7, \Delta \%=0.66, d=0.35$, comparing before and after 8 weeks of training (Table 1).

Analyzing the body fat \% of the participants inside each group, before and after 8 weeks of aerobic training, we observed a significant decrease in percent variation in the Und-Und (before: $14.5 \pm 5.8$; post-training: $13.2 \pm$ 
Table 1 Mean values for age, BMI, and body fat \% of recreational athletes submitted to short-term aerobic training programs

\begin{tabular}{|c|c|c|c|c|c|c|}
\hline \multirow[t]{2}{*}{ Variables. } & \multicolumn{5}{|l|}{ Groups } & \multirow[t]{2}{*}{$p$ value } \\
\hline & Control $(n=16)$ & Und-Und $(n=18)$ & Und-Lin $(n=19)$ & Sta-Und $(n=17)$ & Sta-Lin $(n=18)$ & \\
\hline \multicolumn{7}{|l|}{ Pre-training } \\
\hline Age & $29.0 \pm 0.7$ & $27.7 \pm 9.3$ & $26.3 \pm 6.5$ & $26.6 \pm 7.2$ & $24.3 \pm 4.0$ & 0.86 \\
\hline Range (years) & $28-30$ & $20-35$ & $21-35$ & $20-35$ & $22-32$ & \\
\hline CV (\%) & 2.41 & 35.02 & 24.71 & 27.07 & 16.46 & \\
\hline BMI & $26.0 \pm 0.4$ & $25.8 \pm 4.6$ & $25.8 \pm 5.2$ & $25.1 \pm 3.0$ & $25.9 \pm 4.6$ & 0.99 \\
\hline Range $\left(\mathrm{kg} / \mathrm{m}^{2}\right)$ & $21.33-30.47$ & $20.76-29.92$ & $20.87-28.38$ & $21.21-27.86$ & $19.45-29.04$ & \\
\hline CV (\%) & 1.54 & 17.83 & 20.15 & 11.95 & 17.76 & \\
\hline Body fat & $15.3 \pm 1.9$ & $14.5 \pm 5.8$ & $11.1 \pm 5.9$ & $10.4 \pm 4.3$ & $13.1 \pm 3.8$ & 0.58 \\
\hline Range (\%) & $11.86-22.15$ & $12.37-24.77$ & $9.18-24.83$ & $10,15-23.34$ & $12.88-24.31$ & \\
\hline CV (\%) & 12.42 & 40 & 53.15 & 41.35 & 29.01 & \\
\hline \multicolumn{7}{|c|}{ Post-training (8 weeks) } \\
\hline BMI & $26.2 \pm 0.7$ & $24.9 \pm 4.4 *$ & $25.7 \pm 5.3^{*}$ & $24.8 \pm 3.0$ & $25.8 \pm 4.4^{*}$ & 0.98 \\
\hline Range $\left(\mathrm{kg} / \mathrm{m}^{2}\right)$ & $20.81-28,53$ & $19.65-27.90$ & $20.30-26.36$ & $20.59-28.95$ & $20.19-27.18$ & \\
\hline CV (\%) & 2.67 & 17.67 & 20.62 & 12.10 & 17.05 & \\
\hline$\Delta(\%)$ & 0.66 & -8.70 & -0.32 & -0.87 & -0.12 & \\
\hline$d$ & 0.35 & 0.05 & 0.02 & 0.10 & 0.02 & \\
\hline body fat & $16.5 \pm 2.9$ & $13.2 \pm 6.3^{*}$ & $9.2 \pm 5.0$ & $8.6 \pm 2.9$ & $10.9 \pm 6.3^{*}$ & 0.16 \\
\hline Range (\%) & 14.8-20.6 & $9.45-17.30$ & $8.31-15.73$ & $8.14-12.32$ & $8.89-16.12$ & \\
\hline CV (\%) & 17.57 & 47.73 & 54.35 & 33.72 & 59.80 & \\
\hline$\Delta(\%)$ & 7.85 & -8.78 & -17.58 & -17.08 & -16.45 & \\
\hline$d$ & 0.47 & 0.21 & 0.36 & 0.49 & 0.33 & \\
\hline$p$ & 0.17 & 0.04 & 0.06 & 0.09 & 0.03 & \\
\hline
\end{tabular}

$B M I$ body mass index, $\Delta$ variation, $d$ effect size. Values are indicated as mean \pm standard deviation; ${ }^{*}$ significant difference $(p \leq 0.05)$

6.3; $\Delta \%=-8.78, d=0.21 ; p=0.04)$ and in the Sta-Lin group (before: $13.1 \pm 3.8$; post-training: $10.9 \pm 6.3 ; \Delta \%=$ $-16.45, d=0.33, p=0.03$ ) while a trend to decrease the percent variation was verified in the Und-Lin (before: $11.1 \pm 5.9$; post-training: $9.2 \pm 5.0 ; \Delta \%=-17.58, d=0.36$, $p=0.06$ ) and Sta-Und (before: $10.4 \pm 4.3$; post-training: $8.6 \pm 2.9 ; \quad \Delta \%=-17.08, \quad d=0.49, \quad p=0.09) \quad$ groups (Table 1). No significant changes were observed in the control group. The group with staggered manipulation in the first mesocycle and linear load in the second mesocycle (Sta-Lin) did not change the BMI mean, although promoted a significant decrease in the body fat $\%$ of the participants. The groups with undulatory load in the first mesocycle and linear load in the second mesocycle (Und-Lin) or with staggered manipulation in the first mesocycle and undulatory (Sta-Und) load in the second mesocycle did not significantly change the BMI and the body fat $\%$ of the participants (Table 1 ).

\section{Alterations in the Circulating Levels of Muscle Injury Markers}

When we evaluated the circulating levels of CK in the four groups of participants after 4 weeks of aerobic training,
Und-Und (359.7 \pm 239.4 versus $370.2 \pm 218.3, \Delta \%=2.92 \%$, $d=0.05, p=0.59$ ) did not significantly change (Fig. 5a). In the control, the circulating levels of CK did not change $(151.5 \pm 53.0$ versus $135.0 \pm 32.9, \Delta \%=-9.09 \% d=0.38$, $p=0.30)$ (Fig. 5a). Sta-Und (266.4 \pm 216.0 versus $303.3 \pm$ $165.7, \Delta \%=13.74 \%, d=0.19, p=0.19)$ showed a nonsignificant increase while the Und-Lin $(365.7 \pm 72.4$ versus $418.0 \pm 81.6, \Delta \%=14.31 \%, d=0.68, p=0.01)$ and Sta-Lin $(310.1 \pm 185.4$ versus $378.6 \pm 183.6, \Delta \%=22.06 \%, d=0.37$, $\mathrm{p}=0.01$ ) groups increased significantly the circulating levels of CK (Fig. 5a). From the week 1 to 8 post-training, the Und-Und group did not significantly change the CK levels $(359.7 \pm 239.4$ versus $281.2 \pm 136.6, \Delta \%=-21.83 \%$, $d=0.42, p=0.06)$. No change was verified in the mean levels of $\mathrm{CK}$ in the Und-Lin $(365.7 \pm 72.4$ versus $359.2 \pm$ 65.2, $\Delta \%=-1.78 \%, \quad d=0.09, \quad p=0.62)$ and Sta-Und $(266.4 \pm 216.0$ versus $270.2 \pm 129.1, \Delta \%=1.43 \%, d=0.02$, $p=0.93$ ) groups. However, Sta-Lin group showed a significant increase in the mean values of CK $(310.1 \pm 185.4$ versus $382.6 \pm 197.7, \Delta \%=23.35 \%, d=0.38, p=0.01$ ). In the control, we did not verify significant change in the circulating levels of CK (151.5 \pm 53.0 versus 254.2 \pm 105.6 , $\Delta \%=40.08 \%, d=0.92, p=0.13$ ) (Fig. 5a). 
a

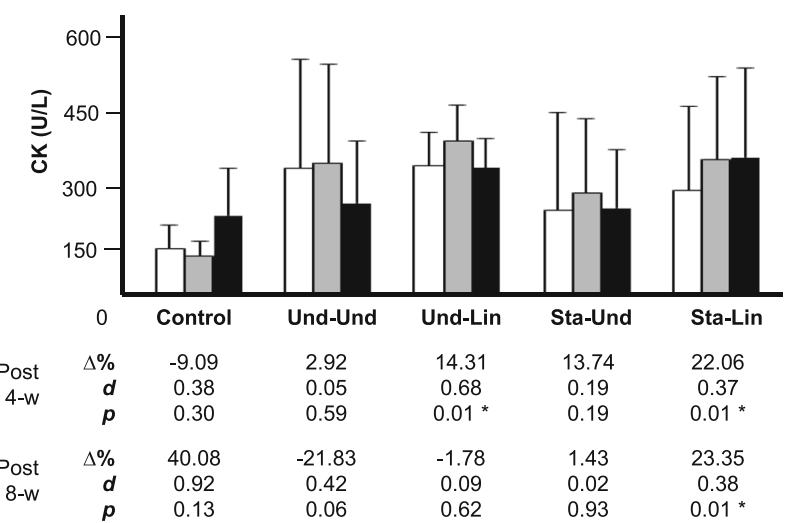

b
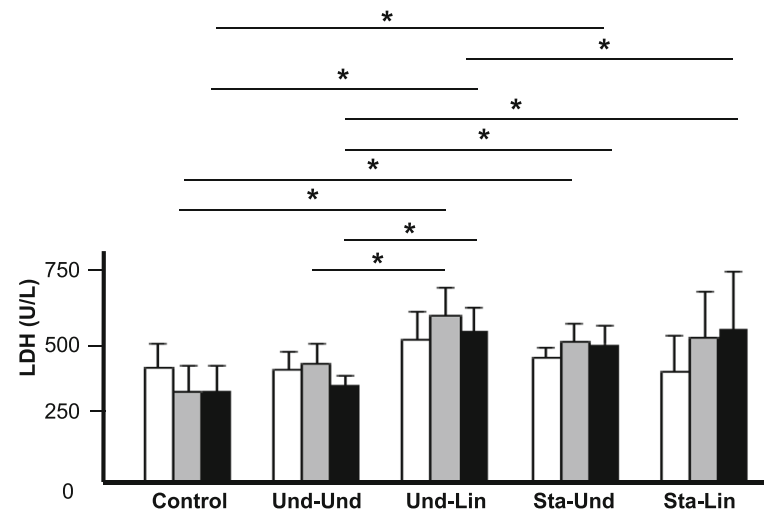

$\square$ Pre-training

$\square$ Post-4 w

Post-8 w

$\begin{array}{rrccccc} & \Delta \% & -20.44 & 5.94 & 16.68 & 12.08 & 27.79 \\ \text { Post } & \boldsymbol{d} & 0.70 & 0.39 & 0.91 & 1.09 & 0.79 \\ \text { 4-w } & \boldsymbol{p} & 0.18 & 0.22 & 0.03 \text { * } & 0.06 & 0.04 \text { * } \\ & & & & & & \\ \text { Post } & \Delta \% & -19.34 & -12.74 & 5.44 & 10.60 & 35.18 \\ \text { 8-w } & \boldsymbol{d} & 0.68 & 1.15 & 0.32 & 0.97 & 1.10 \\ & \boldsymbol{p} & 0.18 & 0.06 & 0.25 & 0.17 & 0.02 \text { * }\end{array}$

Fig. 5 Effects of distinct aerobic trainings and taper-like periods on muscle stress markers in recreational athletes. Mean \pm standard deviation values of a creatine kinase (CK) and $\mathbf{b}$ lactate dehydrogenase (LDH) circulating levels in recreational athletes, before (white bar), post 4 (gray bar, 4-w) or post 8 weeks (black bar, 8-w) of distinct aerobic trainings, as indicated in the legend. Groups: control (without training), undulatory-undulatory (Und-Und), undulatorylinear (Und-Lin), staggered-undulatory (Sta-Und), and staggered-linear (Sta-Lin). $\Delta$, variation; $d$, effect size; * indicates $p \leq 0.05$. Statistical bars indicate comparisons between different groups

In relation to mean values of LDH enzyme, we observed that in all four groups there was an increase from the week 1 to 4 after aerobic training (Fig. 5b). In the control, we verified a trend to decrease circulating $\mathrm{LDH}$ levels $(411.0 \pm 150.7$ versus $327.0 \pm 89.8, \Delta \%=-20.44, d=0.70$, $p=0.18$ ), which could be explained by the lack of training during the 8 -week period. While the Und-Und showed a lower trend in relation to Sta-Und to increase the levels of LDH (Und-Und: $404.2 \pm 60.0$ versus $428.2 \pm 63.5, \Delta \%=$ 5.94, $d=0.39, p=0.22$ ), (Sta-Und: $445.2 \pm 34.9$ versus $499.0 \pm 63.7, \Delta \%=12.08, d=1.09, \mathrm{p}=0.06)$, a significant increase was verified in the Und-Lin and, mainly, in the Sta-Lin group (Und-Lin: $508.5 \pm 92.0$ versus $593.3 \pm 94.9$, $\Delta \%=16.68, d=0.91, p=0.01$ ) (Sta-Lin: $402.0 \pm 121.2$ versus $513.7 \pm 159.9, \Delta \%=27.79, d=0.79, p=0.04$ ) (Fig. 5b). Physiologically, it can be associated with direct muscle injury in individuals submitted to the model without periodization. From the week 1 to 8 post-training, the LDH levels showed a trend to be decreased in the UndUnd group $(404.2 \pm 60.0$ versus $352.7 \pm 29.2, \Delta \%=-$ $12.74 \%, d=1.15, p=0.06)$ or increased in the Und-Lin $(508.5 \pm 92.0$ versus $536.2 \pm 81.6, \Delta \%=5.44, d=0.32, p=$ $0.25)$ and Sta-Und groups $(445.2 \pm 34.9$ versus $492.4 \pm$ 62.6, $\Delta \%=10.60 \%, d=0.97, p=0.17)$. In the Sta-Lin group, we verified a significant increase in the circulating levels of $\mathrm{LDH}(402.0 \pm 121.2$ versus $543.4 \pm 135.4, \Delta \%=$ 35.18, $d=1.10, p=0.02$ ) (Fig. 5b).

After 4 weeks of training, Und-Lin (31.8 \pm 3.4 versus $37.7 \pm 4.03, \quad \Delta \%=18.32, \quad d=1.56, \quad p=0.03), \quad$ Sta-Und $(26.00 \pm 9.2$ versus $29.2 \pm 4.8, \Delta \%=12.31, d=0.38, p=$ $0.05)$, and Sta-Lin $(25.7 \pm 9.9$ versus $33.9 \pm 9.3, \Delta \%=31.67$, $\mathbf{d}=0.85, p=0.02$ ) groups showed a significant increase in 
the levels of AST while Und-Und (26.3 \pm 7.6 versus $28.0 \pm$ $6.2, \Delta \%=6.33, d=0.24, p=0.15$ ) showed only a low trend to increase circulating levels of AST (Fig. 6a). Comparing week 1 to 8 , the levels of AST were also increased mainly in the Und-Lin $(31.8 \pm 3.4$ versus $37.5 \pm 5.3, \Delta \%=17.80$, $d=1.30, p=0.05)$, Sta-Und $(26.00 \pm 9.2$ versus $29.4 \pm 8.4$, $\Delta \%=13.08, d=0.39, p=0.04)$, and Sta-Lin groups (25.7 \pm 9.9 versus $36.7 \pm 7.8, \quad \Delta \%=42.78, \quad d=1.24, \quad p=0.02)$ (Fig. 6a), while Und-Und ( $26.30 \pm 7.60$ versus $27.50 \pm 6.10$, $\Delta \%=4.43, d=0.17, p=0.35$ ) showed a low increase, comparatively. In addition, a non-significant low increase was verified in the Und-Und group $(26.7 \pm 6.1$ versus $28.7 \pm$ 6.0, $\Delta \%=7.50, d=0.33, p=0.23$ ) in the circulating levels of ALT after 4 weeks of training (Fig. 6b). In all other groups, there was a significant increase in the levels of ALT: Und-Lin ( $31.5 \pm 5.2$ versus $37.7 \pm 5.38 .7, \Delta \%=19.58$, $d=0.52, p=0.04)$, Sta-Und $(26.60 \pm 10.5$ versus $32.00 \pm$ 10.20, $\Delta \%=20.32, d=0.89, p=0.03)$, and Sta-Lin $(28.6 \pm$ 7.6 versus $38.4 \pm 7.4, \Delta \%=34.50, d=1.34, p=0.01$ ) groups (Fig. 6b). After 8 weeks of aerobic training, excepting the Und-Und group $(26.7 \pm 6.1$ versus $31.5 \pm 11.1, \Delta \%=18.13$, $d=0.56, p=0.22$ ), the circulating levels of ALT significantly increased in all groups: Und-Lin $(31.5 \pm 5.2$ versus $41.8 \pm 5.30, \quad \Delta \%=32.80, \quad d=1.95, \quad p=0.03), \quad$ Sta-Und $(26.6 \pm 10.5$ versus $38.2 \pm 11.30, \Delta \%=43.61, d=1.08, p=$ $0.02)$, and Sta-Lin $(28.6 \pm 7.3$ versus $47.3 \pm 7.40, \Delta \%=$ 65.50, $d=2.55, p=0.01$ ) (Fig. 6b).

After 4 weeks of training, we did not find significant changes in urea $(\mathrm{U})$ levels in the Und-Und $(25.0 \pm 4.40$ versus $25.5 \pm 3.20, \Delta \%=2.00, d=0.13, p=0.54)$, Und-Lin $(25.80 \pm 5.20$ versus $26.2 \pm 5.50, \Delta \%=1.29, d=0.06, p=$ $0.87)$, and Sta-Und (27.2 \pm 6.0 versus $27.8 \pm 6.50, \Delta \%=$ $2.21, d=0.10, p=0.90)$ groups, although we found a significant increase in the U levels in individuals of the StaLin group $(30.0 \pm 4.8$ versus $31.0 \pm 5.00, \Delta \%=3.33, d=$ $0.20, p=0.04$ ) (Fig. 6c). From week 1 to 8 , no changes were detected in the circulating levels of $U$ in all groups evaluated: Und-Und $(25.0 \pm 4.4$ versus $23.7 \pm 2.50, \Delta \%=$ $-5.33, d=0.38, p=0.45)$, Und-Lin $(25.8 \pm 5.2$ versus $25.00 \pm 4.00, \Delta \%=-3.23, d=0.18, p=0.70)$, Sta-Und $(27.2 \pm 6.00$ versus $27.8 \pm 6.60, \Delta \%=2.21, d=0.10, \mathrm{p}=$ $0.90)$, or Sta-Lin $(30.0 \pm 4.80$ versus $31.70 \pm 4.40, \Delta \%=$ 5.71, $d=0.37, p=0.61$ ) (Fig. 6c).

These data suggest that the Und-Und group had a better efficacy in the recovery of the aerobic training while the Sta-Lin group did not recover well as indicated by the accumulation of serum CK, LDH, AST, ALT enzymes, and U levels.

\section{Circulating Levels of Cortisol, Testosterone, and FT/C Ratio}

We verified only a trend to increase $C$ circulating levels after 4 weeks of aerobic training in the Und-Und group $(359.20 \pm 119.20$ versus $381.90 \pm 119.00, \Delta \%=6.33, d=$
0.19, $p=0.20$ ) (Fig. 7a). On the other hand, a significant increase in the $\mathrm{C}$ levels was observed in recreational athletes after 4 weeks of aerobic exercise in all other groups: Und-Lin $(443.30 \pm 101.30$ versus $498.10 \pm 97.40$, $\Delta \%=12.37, d=0.55, p=0.05)$, Sta-Und (295.20 \pm 95.20 versus $334.00 \pm 92.60, \Delta \%=13.14, d=0.41, p=0.03)$, and Sta-Lin $\quad(331.10 \pm 76.40$ versus $420.70 \pm 59.60, \Delta \%=$ 27.08, $d=1.13, p=0.01$ ) (Fig. 7a). When comparing from week 1 to 8 , we found a trend to decrease the levels of $C$ in the Und-Und group (359.20 \pm 119.20 versus $308.10 \pm$ 89.80, $\Delta \%=-14.21, d=0.49, p=0.10)$ and a nonsignificant increase in the circulating levels of this hormone in the Und-Lin $(443.30 \pm 101.30$ versus $457.20 \pm$ 94.90, $\Delta \%=3.14, d=0.14, \quad p=0.16)$ and Sta-Und $(295.2 \pm 95.30$ versus $355.30 \pm 48.00, \Delta \%=20.37, d=$ $0.84, p=0.10)$ groups. A significant increase in the circulating levels of $\mathrm{C}$ was verified in the Sta-Lin group $(331.10 \pm 76.40$ versus $457.20 \pm 80.60, \Delta \%=38.10, d=$ 1.62, $p=0.01$ ) (Fig. 7a).

Evaluating the circulating levels of FT, we verified that after 4 weeks, no significant change was observed in all groups: Und-Und $(20.30 \pm 2.90$ versus $21.70 \pm 2.10$, $\Delta \%=6.87, d=0.56, p=0.09)$, Und-Lin $(21.60 \pm 5.00$ versus $22.20 \pm 4.20, \Delta \%=2.73, d=0.13, p=0.60)$, Sta-Und $(19.50 \pm 4.00$ versus $19.60 \pm 1.80, \Delta \%=0.37, d=0.02, p=$ $0.95)$, and Sta-Lin $(21.10 \pm 2.70$ versus $21.20 \pm 3.40$, $\Delta \%=0.58, d=0.04, p=0.91$ ) (Fig. 7b). However, from week 1 to 8 , we found a significant increase in the circulating FT levels only in the Und-Und group $(20.30 \pm 2.90$ versus $21.70 \pm 2.10, \Delta \%=14.54, d=1.20, p=0.04$ ) while a trend to increase the levels of this anabolic hormone was verified in the Und-Lin $(21.60 \pm 5.00$ versus $22.80 \pm$ 4.30, $\Delta \%=5.44, d=0.25, p=0.11)$, Sta-Und $(19.50 \pm 4.00$ versus $21.10 \pm 1.80, \Delta \%=8.29, d=0.56, p=0.23)$, and Sta-Lin $(21.10 \pm 2.70$ versus $22.10 \pm 3.10, \Delta \%=4.64, d=$ $0.33, p=0.36$ ) groups (Fig. 7b).

After 4 weeks, no change in the $\mathrm{FT} / \mathrm{C}$ ratio was verified in the Und-Und group $(64.40 \pm 29.00$ versus 64.40 $\pm 29.20, \Delta \%=-0.02, d=0.01, p=0.98$ ) (Fig. 7c). On the other hand, we observed a trend to decrease the $\mathrm{FT} / \mathrm{C}$ ratio in Und-Lin $(51.30 \pm 20.20$ versus $46.00 \pm 13.70, \Delta \%=-10.22, d=0.31, p=0.24)$ and StaUnd $(71.40 \pm 23.00$ versus $63.80 \pm 20.00, \Delta \%=-11.75$, $d=0.39, p=0.13)$ group. A significant decrease in the FT/C ratio was found in the Sta-Lin group $(66.50 \pm$ 16.80 versus $50.90 \pm 6.10, \Delta \%=-23.43, d=1.40, p=$ 0.02) (Fig. 7c). After 8 weeks, only Und-Und group showed a significant increase in the $\mathrm{FT} / \mathrm{C}$ ratio $(64.40 \pm 29.00$ versus $81.80 \pm 26.10, \Delta \%=26.92, d=$ $0.63, p=0.02)$. No change in the FT/C ratio was observed in the Und-Lin group $(51.30 \pm 20.20$ versus $51.90 \pm 17.60, \Delta \%=1.28, d=0.03, p=0.62)$. However, a trend to decrease this ratio was found in the Sta-Und group $(71.40 \pm 23.00$ versus $60.60 \pm 10.80, \Delta \%=-$ 
a

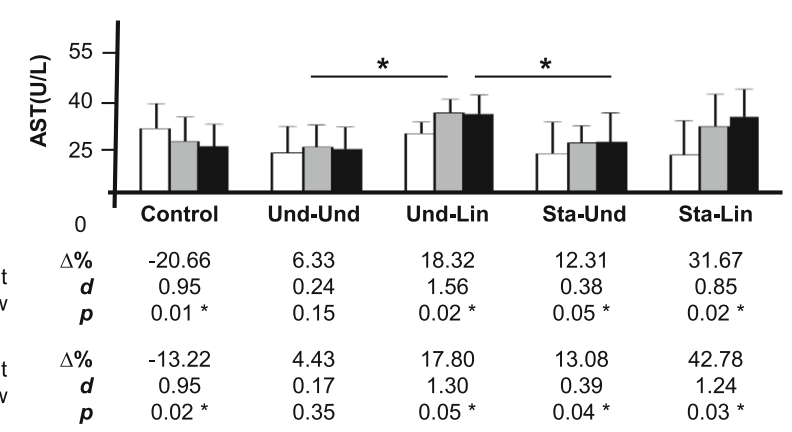

b

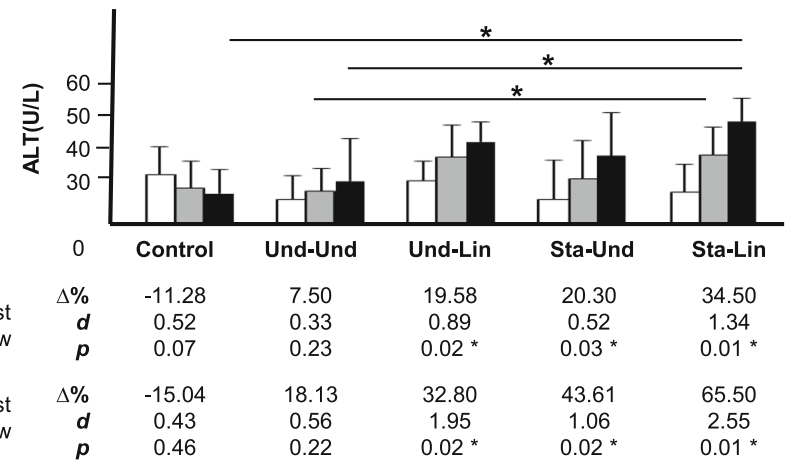

C

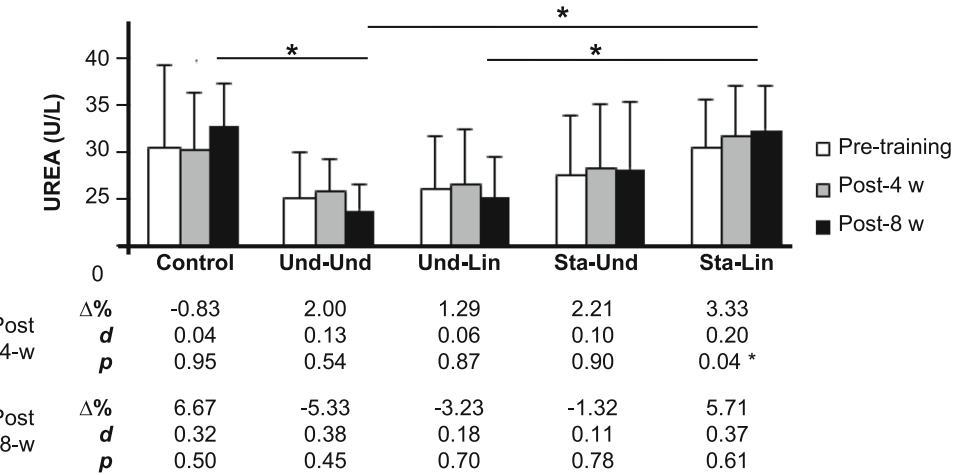

Fig. 6 Alterations in the circulating levels of liver enzymes and urea in recreational athletes submitted to distinct aerobic trainings with taper-like periods. Mean \pm Standard deviation values of $\mathbf{a}$ aspartate aminotransferase (AST), $\mathbf{b}$ alanine aminotransferase (ALT), and $\mathbf{c}$ urea (U) circulating levels in recreational athletes, before (white bar), post 4 (gray bar, 4-w) or post 8 weeks (black bar, 8-w) of distinct aerobic trainings, as indicated in the legend. Groups: control (without training), undulatory-undulatory (Und-Und), undulatory-linear (Und-Lin), staggered-undulatory (Sta-Und), and staggered-linear (Sta-Lin). $\Delta$, variation; $d$, effect size; * indicates $p \leq 0.05$. Statistical bars indicate comparisons between different groups

Table 2 Summary of alterations in $\dot{\mathrm{V}}_{2 \text { max, }}$, hematological, biochemical, and endocrine markers after 8 weeks of aerobic training in recreational athletes submitted to distinct periodization models

\begin{tabular}{|c|c|c|c|c|c|c|c|c|c|c|c|c|}
\hline Periodization & $\begin{array}{l}\dot{\mathrm{VO}_{2 \max }} \\
(\mathrm{m} / \mathrm{mg} / \\
\mathrm{min}) \\
\text { Mean }\end{array}$ & $\begin{array}{l}\mathrm{Hb} \\
(\mathrm{g} / \\
\mathrm{dl}) \\
\Delta \% \\
\end{array}$ & $\begin{array}{l}\mathrm{Ht} \\
(\%) \\
\Delta \%\end{array}$ & $\begin{array}{l}\text { MCHC } \\
(\%) \\
\Delta \%\end{array}$ & $\begin{array}{l}\text { CK } \\
(\mathrm{U} / \\
\mathrm{L}) \\
\Delta \% \\
\end{array}$ & $\begin{array}{l}\mathrm{LDH} \\
(\mathrm{U} / \\
\mathrm{L}) \\
\Delta \% \\
\end{array}$ & $\begin{array}{l}\text { AST } \\
(\mathrm{U} / \\
\mathrm{L}) \\
\Delta \% \\
\end{array}$ & $\begin{array}{l}\text { ALT } \\
(\mathrm{U} / \\
\mathrm{L}) \\
\Delta \% \\
\end{array}$ & $\begin{array}{l}\text { Urea } \\
(\mathrm{U} / \\
\mathrm{L}) \\
\Delta \% \\
\end{array}$ & $\begin{array}{l}\mathrm{C} \\
\text { (nmol/ } \\
\mathrm{L} \text { ) } \\
\Delta \% \\
\end{array}$ & $\begin{array}{l}\text { T } \\
\text { (nmol/ } \\
\mathrm{L} \text { ) } \\
\Delta \% \\
\end{array}$ & $\begin{array}{l}\text { FT/ } \\
\text { C } \\
\text { ratio }\end{array}$ \\
\hline Und-Und & $\uparrow^{*}$ & $\uparrow$ & $\uparrow$ & $\uparrow^{*}$ & $\downarrow$ & $\downarrow$ & $\uparrow$ & $\uparrow$ & $\downarrow$ & $\downarrow$ & $\uparrow^{*}$ & $\uparrow^{*}$ \\
\hline Und-Lin & $\uparrow^{*}$ & $\uparrow^{*}$ & $\uparrow$ & $\uparrow$ & $=$ & $\uparrow$ & $\uparrow^{*}$ & $\uparrow^{*}$ & $\downarrow$ & $\uparrow$ & $\uparrow$ & $=$ \\
\hline Sta-Und & $\uparrow^{*}$ & $\uparrow^{*}$ & $=$ & $\uparrow$ & $=$ & $\uparrow$ & $\uparrow^{*}$ & $\uparrow^{*}$ & $\uparrow$ & $\uparrow$ & $\uparrow$ & $\downarrow$ \\
\hline Sta-Lin & $\uparrow^{*}$ & $=$ & $\downarrow$ & $\uparrow$ & $\uparrow^{*}$ & $\uparrow^{*}$ & $\uparrow^{*}$ & $\uparrow^{*}$ & $\uparrow$ & $\uparrow^{*}$ & $\uparrow$ & $\downarrow^{*}$ \\
\hline
\end{tabular}

* Indicates statistical difference ( $p \leq 0.05$ ) in mean values, $\Delta \%$ or FT/C ratio between the pre-training and post-training period; $\uparrow$ means trend to increase; $\downarrow$ means trend to decrease; $=$ means similar values between the pre-training and post-training period 


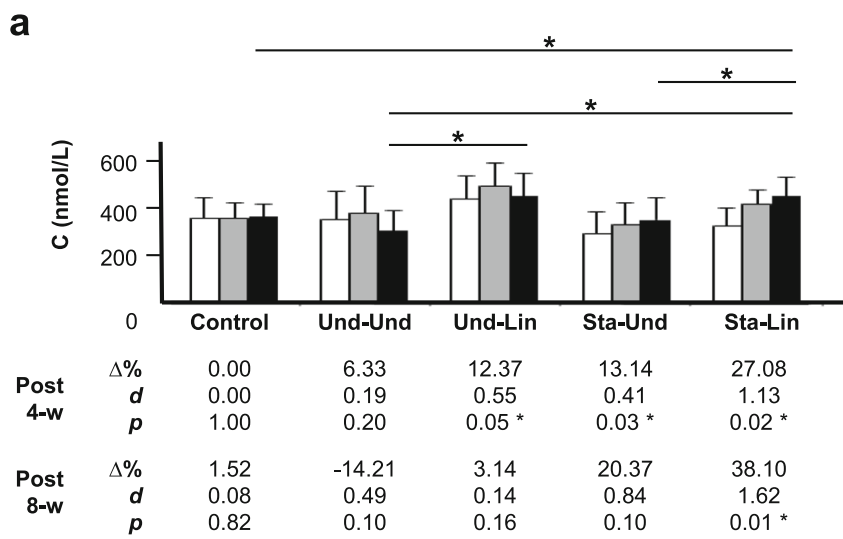

b

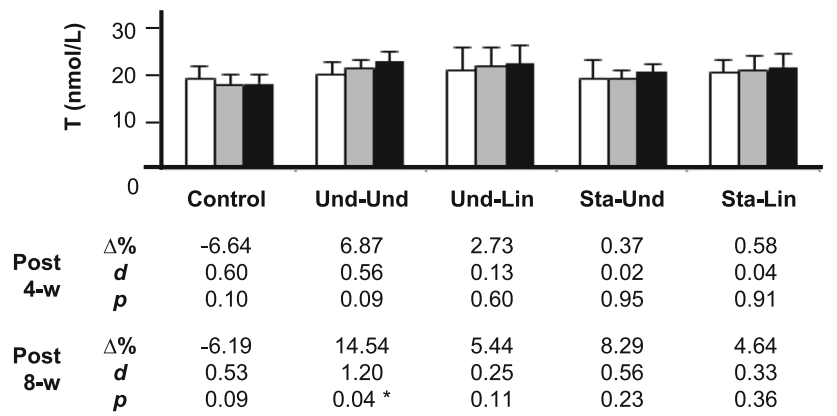

C

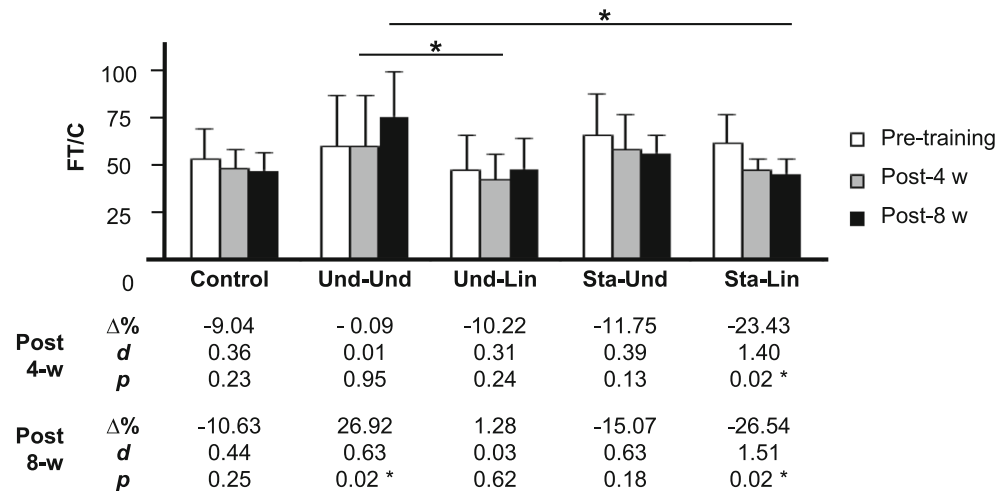

Fig. 7 Effects of distinct aerobic trainings and taper-like periods on markers for muscle catabolism and anabolism in recreational athletes. Mean \pm standard deviation values of $\mathbf{a}$ cortisol (C) and $\mathbf{b}$ testosterone (T) circulating levels and of $\mathbf{c}$ free testosterone/cortisol ratio (FT/C) in recreational athletes, before (white bar), post 4 (gray bar, 4-w) or post 8 weeks (black bar, 8-w) of distinct aerobic trainings, as indicated in the legend. Groups: control (without training), undulatory-undulatory (Und-Und), undulatory-linear (Und-Lin), staggered-undulatory (Sta-Und), and staggered-linear (Sta-Lin). $\Delta$, variation; $d$, effect size; * indicates $p \leq 0.05$. Statistical bars indicate comparisons between different groups

$15.07, d=0.63, p=0.18)$. The $\mathrm{FT} / \mathrm{C}$ ratio significantly decreased in the Sta-Lin group $(66.50 \pm 16.80$ versus $48.90 \pm 8.10, \Delta \%=-26.54, d=1.51, p=0.02$ ) (Fig. 7c). These results indicate that Sta-Lin model increased catabolism and was physiological deleterious, promoting more muscle injury and inefficient recovery as well as confirmed Und-Und as the best model for muscle recovery in recreational athletes submitted to distinct short-term aerobic training (Table 2).

\section{Discussion}

We investigated the aerobic fitness of healthy males after aerobic exercise using a novel model of analysis, where tapering-like period was applied in the final week of distinct aerobic training models, including undulatory and nonundulatory load manipulations. We evaluated $\dot{\mathrm{V}}_{2 \max }$ and the circulating levels of hematological, biochemical, and hormonal markers before, during, and after aerobic training of recreational athletes. Our data indicate that after 8 weeks 
of training, (a) the greater cardiorespiratory fitness among all training groups was associated with the group that followed undulatory load manipulation with both daily and weekly loads (the und-und group) and reduced load in the final week, (b) the lower muscle injury and best recovery was also verified in the Und-Und group, and (c) staggered load manipulation, without load reduction in the final week of training, seems to promote inadequate recovery, as mainly observed in the Sta-Lin group.

In our study, we were limited to use $\dot{\mathrm{V}}_{2 \max }$ as parameter to prescribe exercise intensity to improve cardiorespiratory fitness [66-69]. Different groups indicated a low correlation between $\mathrm{Fc}_{\max }$ and $\%$ of $\dot{\mathrm{V}}{ }_{2 \max }$. In this regard, Buchheit et al. verified that heart rate (HR) at rest during and after exercise tests served as parameters to verify the aerobic performance in healthy runners [79]. However, a large percentage variation was observed in the \% of $\dot{\mathrm{V}} \mathrm{O}_{2 \max }$ (2 to $19 \%$ ) of health men, after an individual endurance training program [80]. On the other hand, Katch et al. analyzed the $\%$ of $\dot{\mathrm{V}}_{2 \max }$, heart rate, and metabolic acidosis in the intensity of $60 \%, 70 \%$, and $80 \%$ in 31 individuals submitted to a progressive cycle ergometer test $\left(\mathrm{V}_{2 m a x}\right.$ range was between 37.8 and 68.8). These authors verified that $60 \%, 70 \%$, and $80 \%$ of the maximum heart rate corresponded to $36 \%, 48 \%$, and $62 \%$ of $\dot{\mathrm{VO}}_{2 \max }$, respectively, and concluded that metabolic acidosis is not constant among the participants exercising at the same relative percentage of HRmax, thus indicating a low prediction between \% of $\dot{\mathrm{VO}}_{2 \max }$ and HR [81]. In this regard, it is worth noting that Pollock previously found similar values [82]. Additionally, Wolpern et al. after observing healthy but sedentary men and women $(n=36)$ in a treadmill test concluded that the anaerobic threshold was the most efficient parameter to analyze exercise intensity when compared to $\%$ of HR reserve [56]. Although some authors indicate a low correlation between Fcmax and \% of $\dot{\mathrm{VO}}_{2 \max }$, Garber indicated that the intensity of $\mathrm{VO}_{2 \max }$ in percentages $(64 \%$ to $91 \%$ ) corresponds to $76 \%$ to $96 \%$ of Fcmax \%, respectively, among individuals of 20 to 39 years of age [45]. Furthermore, the American College of Sport Medicine [64] recommend that the appropriate intensity to increase cardiorespiratory fitness for healthy adults should be $60-90 \%$ of Fcmax, which correspond to 50-85\% of maximum oxygen consumption $\left(\dot{\mathrm{V}}_{2 \max }\right)$. On the other hand, these variables are not related to the individual metabolic responses of blood lactate, and can vary individually, as a form of adaptation, in each exercise session [83].

Despite all training groups showing significant improvement in $\dot{\mathrm{VO}}_{2 \max }$, after 8 weeks of training, the gain $(22.15 \%)$ and the largest effect size $(d=1.14)$ in $\dot{\mathrm{V}}_{2 \max }$ were more evidenced in the Und-und group. Based on $\Delta \%$ comparison, Und-Lin group presented greater gain (16.01\%) than Sta-und group (11.47\%) while Sta-Lin group presented the lowest improvement in $\dot{\mathrm{VO}}_{2 \max }$
(11.16\%). These findings are in agreement with our previous work [57] showing a significant increase in the aerobic fitness of these same training groups of recreational athletes after 8 weeks of running, where the Und-und group showed the better distance performance [57]. We could explain the greatest improvement in $\dot{\mathrm{V}}_{2 \max }$ in the Und-Und and Und-Lin groups by the reduction in the weekly volume of training, as our group previously suggested, considering the intervention with a microcycle for best recovery, avoiding detraining [57]. In agreement with our data, an increase of $7.92 \%$ of $\dot{\mathrm{VO}}_{2 \max }$ was observed in recreational exercise practitioners after a week of taper period [51]. In another study with recreational runners, an increase of $5.05 \%$ in $\dot{\mathrm{VO}}_{2 \max }$ was observed after 13 weeks of training followed by 3 weeks of taper [52]. Other researchers verified a $\dot{\mathrm{VO}}_{2 \max }$ gain of $3.07 \%$ in athletes following long-distance running and 7 days of tapering, with $85 \%$ of volume reduction without decreasing weekly training sessions [33]. Moreover, a review showed that of 13 articles analyzed, ten demonstrated increased $\mathrm{VO}_{2 \max }$ with training tapering varying from 7 until 28 days; two showed no effect and one showed a trend to reduce $\dot{\mathrm{V}}_{2 \max }$ in athletes, including swimmers, cyclist, triathletes, and runners [49]. These data indicate that tapering ameliorates aerobic fitness in recreational runners as that observed in athletes.

In our study, we verified that recreational athletes submitted to Und-Und and Und-Lin taper-like periods present high increase in $\dot{\mathrm{V}} \mathrm{O}_{2 \max }$ gain and trend to increase $\mathrm{Ht} \%$ and $\mathrm{Hb}$ circulating levels after 8 weeks of training. Schumacher and colleagues [84] showed an association between the regular practice of exercise with elevated circulating levels of $\mathrm{Hb}$ and $\mathrm{Ht} \%$ with improvement in $\mathrm{O}_{2}$ transport and $\dot{\mathrm{VO}}_{2 \max }$ in athletes, a condition that can be altered according to the exercise intensity. In our study, it is possible to consider that a reduced volume of training in the Und-Und and UndLin taper-like periods could decrease hemolysis [26, 33, 85] induced by aerobic training for 8 weeks with the final week of tapering-like period. Yamamoto and colleagues [3] reported increased mean concentrations of $\mathrm{Hb}$ and $\mathrm{Ht} \%$ in young swimmers after the tapering off period of 1 week. On the other hand, another group showed that male swimmers presented a trend to decrease $\mathrm{Ht} \%, \mathrm{Hb}$ levels and a significant reduction of MCHC after 4 weeks of taper [86]. However, Mujika and collaborators [85] verified an increase of $\mathrm{MCHC}$ in athletes submitted to high load of training with a decrease in the taper period of 4 weeks. The authors also observed a trend to decrease $\mathrm{Hb}$ levels in the final taper period. These studies suggest that the taper duration, as well as the time of previous training, might influence negatively on $\mathrm{O}_{2}$ consumption in both athletes and recreational athletes. 
We verified a trend to reduce the levels of $\mathrm{Hb}$ and $\mathrm{Ht}$ $\%$ in the Sta-Lin group. Possibly, an increased volemia [87] could occur in the Sta-Lin group due to an inefficient recovery. In this regard, other groups have shown a trend to decrease $\mathrm{Ht} \%$ and the $\mathrm{Hb}$ circulating levels in competitive swimmers submitted to intense training [3, 88]. Moreover, it has been described that decreased $\mathrm{Ht} \%$ can occur in athletes using elevated loads of endurance training in association with plasma volume expansion [89]. For instance, it could lead to increase in the levels of aldosterone and activation of plasmatic proteins [90] and to a reduction in $\mathrm{Fe}^{++}$levels, as observed in long distance runners [91].

In relation to body fat \% after aerobic training, we observed a significant decrease in all groups. The BMI showed a trend to decrease more in the Und-Und group than in the Und-Lin, Sta-Und, and Sta-Lin groups. Other studies also verified a trend to decrease body fat $\%$ and BMI in recreational athletes following aerobic training periodization with moderate intensity [57, 92, 93]. In addition, it was verified an inverse correlation between $\mathrm{BMI}$ and body fat \% with $\dot{\mathrm{V}} \mathrm{O}_{2 \max }$ levels while the free fat mass was positively correlated with the $\dot{\mathrm{VO}}_{2 \max }$ [94]. In this scenarium, regular activity might contribute to decrease body fat \% leading to an increase in free fat mass and $\dot{\mathrm{V}}_{2 \max }$ levels [95].

In our study, we measured the circulating levels of CK and LDH in recreational athletes submitted to 8 weeks of training. We observed that the groups that had taper-like periods in their training showed a trend to decrease the circulating levels of CK while Sta-Lin group increased the circulating levels of this enzyme. In this context, it is known that running is considered predominantly an eccentric action, which means that the load is above muscle capacity to sustain it promoting more muscle microlesions in comparison with concentric and isometric actions [96, 97]. These muscle microlesions can lead to "hemolysis by impact" [98]. Physiologically, these lesions could be explained by the higher passive tension of the connective tissue on the muscle fibers $[99,100]$. In addition, eccentric actions recrute less motor units, i.e., alpha-neurons, than concentric actions but induces elevated mechanic stress in the muscle fibers thus leading to higher tension [100]. Considering that running is predominantly eccentric, it is possible to evaluate muscle injury measuring the circulating levels of CK, a biomarker of stress and change in muscle activity in athletes $[101,102]$ and recreational athletes [103].

CK may denote a recent state of muscle deterioration due to physical exercise overloading. In this sense, the application of large loads of volume and/or intensity has led to considerable increases in the concentrations of CK circulating levels [100]. On the other hand, the taper period or recovery microcycles are the phases of training that provide significant muscle recovery and may promote a significant reduction in serum CK concentrations [104]. CK reduction was also seen in runners after 6 days [105]. These effects could possibly be due to the adaptation to the physical exercise during the training.

We observed that the adoption of microcycles of recovery in the Und-Und, Und-Lin, and Sta-Und groups showed a trend to reduce $\mathrm{CK}$ concentration in the serum of recreational athletes submitted to 8 weeks of running. This effect was mainly observed in the UndUnd group. Although the peak in the concentration of CK occurs after $24 \mathrm{~h}$ of exercise, it may extend for up to $72 \mathrm{~h}$, being persistent. In high concentrations, CK is considered an important sign of chronic fatigue [102]. A reduction of around $6.09 \%$ of CK in runners was also observed after applying a week of step tapering off, when there is a sudden reduction in the training workload [105]. Others also observed an association between a trend to decrease CK levels and performance improvement in the taper period in runners [32] and swimmers [106].

We also verified that Und-Und group presented the highest trend to decline the circulating levels of LDH in recreational athletes after 8 weeks of running, as compared with the other training groups analyzed. On the other hand, the Sta-Lin group expressed a trend to increase LDH circulating levels. In this regard, the increase in the concentration of LDH in the blood may denote cell injury due to strenuous effort $[8,15]$. These data allow us to propose that Und-Und model might be better tolerated and Sta-Lin program might promote more muscle injury. Our results showing a strong trend to decline $\mathrm{CK}$ and $\mathrm{LDH}$ circulating levels in recreational athletes after a specific taper-like period suggest that the Und-Und model might be more effective to prevent overtraining and stress due to oscillations between volume/intensity and recovery. Possibly, with a longer period of training, we could verify significant statistic changes in the circulating levels of $\mathrm{CK}$ and LDH enzymes in recreational athletes.

In relation to the circulating levels of AST and ALT, we verified that the Und-Und group showed the lowest trend to increase these parameters in the fourth and eighth weeks of training, when compared with the other groups. These changes can be explained by a possible effect of stimulus and recovery in the Und-Und model of periodization, i.e., taper-like model, which is the decrease of loads in the eighth week. In this condition, higher disponibility of ATP could contribute to maintain the cellular membrane integrity [3] and decrease exocytosis of AST and ALT to the circulation. Banister and colleagues also observed a decrease of AST besides CK and LDH in the taper period in athletes (32 days) [14]. Furthermore, a study with swimmers using two different 
taper periods showed a decrease in ALT and AST between the fourth and the ninth day [3].

The levels of AST and ALT significantly increased in the Sta-Lin group after 4 and 8 weeks of training. Skenderi et al. also verified increased gains in the circulating levels of AST and ALT in runners of long distance, and these effects were associated with an increase in the circulating levels of CK and LDH enzymes [107]. Additionally, high levels of AST and ALT were observed when runners of long duration performed extreme exercise [108]. It was verified a trend to increase ALT and a significant increase of AST in trained recreational athletes, after aerobic exercise [109]. In this context, possibly, the efflux of AST and ALT enzymes to blood circulation could be influenced by duration, type of exercise, intensity, and adaptation to physical training [3].

We evaluated the levels of $U$ in our study because $U$ as well as uric acid are formed during protein catabolism [110] and may indicate, indirectly, the state of proteolysis [111] and intensity monitoring, as described in exercise of endurance $[2,102,112]$. In addition, the verification of $U$ levels may serve as a supplementary analysis of the anabolic/catabolic state of training [113] and as an indicator of muscle injury [14].

The levels of $U$ showed a trend to increase in all groups evaluated in our study after 4 weeks of training. Excepting Sta-Lin group, all others, including Und-Und, Und-Lin, and Sta-Und groups, presented a trend to decline from the first to the eighth week. Similar to UndUnd and Und-Lin taper-like models, Coutts et al. observed a decrease in the circulating $U$ levels in trained triathletes after a 2-week taper period, both in the normal and overload training groups [5].

The $\mathrm{U}$ level in the Sta-Lin group was significantly higher than in the Und-Und group after 8 weeks of training. In this regard, it is valid to point out that the $\mathrm{U}$ concentration can be increased after an intense effort. This alteration has been associated with a reduction in the renal blood flow, low glomerular filtration, and increased protein catabolism [114, 115]. In recreational athletes, after long-distance running, it is observed an increase in the serum $U$ concentration and glomerular filtration in the first $24 \mathrm{~h}$. After this period, while U concentration is still increased, the glomerular filtration decreases $(p<0.05)$ [116].

The taper period normally leads to an increase in the anabolism and a decrease in the catabolism, which can be verified by an increase in the FT levels and a decrease in the $C$ levels, with performance improvement $[5,117]$. All groups analyzed in our study presented a trend to increase $\mathrm{C}$ after 4 weeks of aerobic exercise. However, the levels of this hormone decreased in the Und-Und and Und-Lin groups in the taper-like period, after 8 weeks of training. Previous works with swimmers and triathletes showed a trend to decrease $\mathrm{C}$ levels associated with an increase in the performance after the taper period [5, 118]. The lower responses in $C$ levels might be related to adaptation to the undulatory effects and load decrease in the taper-like period in the final week of training. In this context, other findings with cyclists and young rowers showed a trend to increase $\mathrm{C}$ levels with an increase in the performance after the taper period [119, 120]. The reduction of $C$ levels can be due to a decrease in the protein catabolism favoring protein aggregation and reduction in their degradation [121]. In this case, it could be a mechanism of supercompensation during the taper-like period.

Differently, we verified that the Sta-Und and Sta-Lin groups showed an increase in the C levels after 8 weeks of training. Possibly, these groups did not present an efficient recovery, i.e., they did not have an anabolic response in the final week of training. Moreover, cortisol can promote an increase in the concentration of free fat acids and amino acids in the blood plasma when stimulating lipid catabolism and gluconeogenesis and synthesis of plasma and liver proteins [122], which is relevant for endurance athletes, for instance.

The Und-Und and Sta-Lin groups presented, respectively, the higher and lower trend to increase the levels of FT after eight weeks of training. Moreover, the Und-Lin and Sta-Und groups also showed an increase in the circulating testosterone $(\mathrm{T})$ levels, even without the taperlike period in the final week of training. These data are in agreement with previous findings showing an increase in the plasma $\mathrm{T}$ concentration after 10 days of tapering in cyclists [123]. Although there was no load decrease in Sta-Und, this group showed an undulatory feature inside the weeks, the macrocycle. This effect on $\mathrm{T}$ levels might contribute for a stimulatory effect on recovery, which is characteristic of undulation load. In this context, trends to increase the circulating levels of total $\mathrm{T}$ and FT were related with the load intensity in the training [124], mainly in the taper period [32, 106, 118, 123], possibly due to the supercompensation recovery effects.

The FT/C ratio has been used as an important marker of training stress in different types of exercise $[5,9,10$, 32]. In our study, the FT/C ratio in recreational athletes of the Und-Und and Sta-Lin groups was significantly increased and decreased, respectively, after 8 weeks of training. In agreement with our findings in the UndUnd-group, Coutts and colleagues showed a trend to increase the FT/C ratio in triathletes [5], which could be explained by the metabolic scenarium in favor of the protein anabolism [125]. In relation to the opposite effect observed in the Sta-Lin group, with increased C and decreased $\mathrm{T}$ circulating levels, it could be explained by a catabolic effect during the aerobic training. In future studies, it would be interesting to evaluate the maximal 
lactate steady state which is considered a gold standard aerobic capacity marker and correlate through its threshold with $\mathrm{VO}_{2 \max }$. Moreover, analyses of oxidative stress markers, circulating levels of lipid peroxidation, as well as proinflammatory cytokines would help to better understand the physiological changes in the body of recreational athletes in response to modulations of distinct training loads. Conjointly, it might contribute to better understand the influence of trainings on muscle recovery and for physical educators and professionals to prescribe trainings to optimize physical adaptation of recreational athletes in running events.

\section{Conclusion}

We verified that application of load reduction and taperlike period in the final week of short-term aerobic training interfere in the aerobic fitness of recreational athletes, being the effects related to changes in their general biological background. Our results indicate that recreational runners who perform physical exercises five times a week can increase their cardiorespiratory fitness, decrease muscle injuries, and increase FT/C ratio when they perform undulatory cycles weekly and monthly with decrease in volumes after 4 weeks of training. On the other hand, without taper-like periods, using staggered load manipulation, there is an increase in catabolism and muscle injury markers as well as a decreased FT/C ratio, thus indicating inefficient recovery.

\section{Abbreviations}

ALT: Alanine aminotransferase; ANOVA: Analysis of variance; AST: Aspartate aminotransferase; BMl: Body mass index; C: Cortisol; CK: Creatine kinase; EDTA: Ethylenediaminetetraacetate; Hb: Hemoglobin; Ht: Hematocrit; LDH: Lactate dehydrogenase; MCHC: Mean corpuscular hemoglobin concentration; Sta-Lin: Staggered-linear; Sta-Und: Staggered-undulatory; T: Testosterone; T/ C: Testosterone/cortisol ratio; U: Urea; Und-Lin: Undulatory-linear; UndUnd: Undulatory-undulatory; VE: Minute ventilation; $\mathrm{VO}_{2 \text { max }}$ : Maximal oxygen uptake

\section{Acknowledgments}

The authors thank all colleagues that contributed with fruitful discussions.

\section{Funding}

This study had no financial resources.

\section{Availability of Data and Materials}

The datasets used and/or analyzed during the current study are available from the corresponding author on reasonable request.

\section{Authors' Contributions}

Conceptualization, methodology, and investigation: PC, AP. Data curation: PC, $M G, V D M C, A P$. Data analysis and writing: PC, RS, AJP, MG, RL, RM, FB, VDMC, AP. All authors read and approved the final manuscript.

\section{Ethics Approval and Consent to Participate}

The study details and protocol were approved by the Research Ethics Committee (number 024/10) of University Hospital Clementino Fraga Filho, of the Federal University of Rio de Janeiro.

\section{Consent for Publication}

Not applicable.

\section{Competing Interests}

The authors, Paulo Costa, Roberto Simão, Anselmo Perez, Maurício Gama, Rogério Lanchtermacher, Reinaldo Musialowski, Fábio Braga, Valéria de Mello Coelho, Alexandre Palma, declare that they have no competing interests.

\section{Publisher's Note}

Springer Nature remains neutral with regard to jurisdictional claims in published maps and institutional affiliations.

\section{Author details}

${ }^{1}$ School of Physical Education and Sports, Rio de Janeiro Federal University, Av. Carlos Chagas Filho, 540 - Cidade Universitária, Rio de Janeiro, RJ 21940-901, Brazil. "2Laboratory of Immunophysiology, Institute of Biomedical Sciences, Health Sciences Center, Federal University of Rio de Janeiro, Rio de Janeiro, Brazil. ${ }^{3}$ Laboratory of Exercise Physiology, Federal University of Espirito Santo, Vitoria, ES, Brazil.

Received: 21 January 2019 Accepted: 11 June 2019

Published online: 22 July 2019

\section{References}

1. Kuipers $\mathrm{H}$, Keizer HA. Overtraining in elite athletes. Review and directions for the future. Sports Med. 1988;6(2):79-92.

2. Fry RW, Morton AR, Keast D. Overtraining in athletes. An update. Sports Med. 1991;12:32-65.

3. Yamamoto Y, Mutoh Y, Miyashita M. Hematological and biochemical indices during the tapering period of competitive swimmers. In: Swimming Science V. Champaign: Human Kinetics; 1988. p. 269-75.

4. Budgett R. Fatigue and underperformance in athletes: the overtraining syndrome. Br J Sports Med. 1998;32:107-10.

5. Coutts AJ, Wallace LK, Slattery KM. Monitoring changes in performance, physiology, biochemistry, and psychology during overreaching and recovery in triathletes. Int J Sports Med. 2007;28:125-34.

6. Armstrong $L E$, VanHeest JL. The unknown mechanism of the overtraining syndrome: clues from depression and psychoneuroimmunology. Sports Med. 2002;32(3):185-209.

7. Costill DL, Flynn MG, Kirwan JP, et al. Effects of repeated days of intensified training on muscle glycogen and swimming performance. Med Sci Sports Exerc. 1988;20(3):249-54

8. Jeukendrup A, Hesselink M. Overtraining - what do lactate curves tell us? Br J Sports Med. 1994;28(4):239-40.

9. Kuoppasalmi K, Adlercreutz H. Interaction between catabolic and anabolic steroid hormones in muscular exercise. In: Fotherby K, Pal SB, editors. Exercise Endocrinology. Berlin: de Gruyter; 1984. p. 65-98.

10. Adlercreutz H, Hirkonen M, Kuoppasalmi K, et al. Effect of training on plasma anabolic and catabolic steroid hormones and their response during physical exercise. Int J Sports Med. 1986;7(Suppl. 1):27-8.

11. Urhausen A, Kindermann W. Diagnosis of overtraining - what tools do we have? Sports Med. 2002;32:95-102.

12. Margonis K, Fatouros IG, Jamurtas $A Z$, et al. Oxidative stress biomarkers responses to physical overtraining: implications for diagnosis. Free Radic Biol Med. 2007:43(6):901-10.

13. Gouarné C, Groussard C, Gratas-Delamarche A, Delamarche P, Duclos M. Overnight urinary cortisol and cortisone add new insights into adaptation to training. Med Sci Sports Exerc. 2005:37(7):1157-67.

14. Banister EW, Morton RH, Fitz-Clarke J. Dose/response effects of exercise modeled from training: physical and biochemical measures. Ann Physiol Anthropol. 1999;11(3):345-56.

15. Gleeson M. Biochemical and immunological markers of over-training. 」 Sports Sci Med. 2002;1 (2):31-41.

16. Vervoorn C, Quist AM, Vermulst $\sqcup$, Erich WB, de Vries WR, Thiijsen JH. The behaviour of the plasma free testosterone/cortisol ratio during a season of elite rowing training. Int J Sports Med. 1991;12(3):257-63.

17. Hackney AC, Walz EA. Hormonal adaptation and the stress of exercise training: the role of glucocorticoids. Trends Sport Sci. 2013;20(4):165-71.

18. Urhausen A, Gabriel HH, Kindermann W. Impaired pituitary hormonal response to exhaustive exercise in overtrained endurance athletes. Med Sci Sports Exerc. 1998:30(3):407-14.

19. Duclos M, Corcuff JB, Pehourcq F, Tabarin A. Decreased pituitary sensitivity to glucocorticoids in endurance-trained men. Eur J Endocrinol. 2001;144(4):363-8. 
20. Meeusen R, Duclos M, Foster C, et al. Prevention, diagnosis, and treatment of the overtraining syndrome: joint consensus statement of the European College of Sport Science and the American College of Sports Medicine. Med Sci Sports Exerc. 2013;45(1):186-205.

21. Meeusen R, Duclos M, Gleeson M, Rietjens G, Steinacker J, Urhausen A. Prevention, diagnosis and treatment of the overtraining syndrome: ECSS position statement "task force". Eur J Sport Sci. 2006;6(1):1-14.

22. Jakovlev NN. Sportbiochemie. Leipzig: Barth; 1977.

23. Reader K. Carl Weigert und seine Bedeutung fuer die medizinische Wissenschaft unserer Zeit. Whitefsh: Kessinger Publishing, LLC; 2010. p. 146.

24. Houmard JA, Kirwan JP, Flynn MG, Mitchell JB. Effects of reduced training on submaximal and maximal running responses. Int J Sports Med. 1989; 10(1):30-3.

25. Grivas GV. The effects of tapering on performance in elite endurance runners: a systematic review. Int J Sports Sci. 2018;8(1):8-13.

26. Neufer PD. The effect of detraining and reduced training on the physiological adaptations to aerobic exercise training. Sports Med. 1989;8(5): 302-20.

27. Mujika I, Padilla S. Detraining: loss of training-induced physiological and performance adaptations. Part I. Sports Med. 2000;30(2):79-87.

28. Mujika I, Padilla S. Detraining: loss of training-induced physiological and performance adaptations. Part II: long term insufficient training stimulus. Sports Med. 2000;30(3):145-54.

29. Borresen J, Lambert MI. The quantification of training load, the training response and the effect on performance. Sports Med. 2009;39:779-95.

30. Skovgaard C, Almquist NW, Kvorning T, Christensen PM, Bangsbo J. Effect of tapering after a period of high-volume sprint interval training on running performance and muscular adaptations in moderately trained runners. J Appl Physiol. 2018;124(2):259-67.

31. Mujika I, Padilla S. Scientific bases for precompetition tapering strategies. Med Sci Sports Exerc. 2003;35:1182-7.

32. Mujika I, Goya A, Ruiz E, Grijalba A, Santisteban J, Padilla S. Physiological and performance responses to a 6-day taper in middle-distance runners: influence of training frequency. Int J Sports Med. 2002;23:367-73.

33. Houmard JA. Impact of reduced training on performance in endurance athletes. Sports Med. 1991;12:380-93.

34. Spilsbury KL, Fudge BW, Ingham SA, Faulkner SH, Nimmo MA. Tapering strategies in elite British endurance runners. Eur J Sport Sci. 2014;15(5):1-7.

35. Zarkadas PC, Carter JB, Banister EW. Modelling the effect of taper on performance, maximal oxygen uptake, and the anaerobic threshold in endurance athletes. Adv Exp Med Biol. 1995;393:179-86.

36. Mujika I. The influence of training characteristics and tapering on the adaptation in highly trained individuals: a review. Int J Sports Med. 1998; 19(7):439-46.

37. Mujika I, Padilla S. Swimming performance changes during the final 3 weeks of training leading to the Sydney 2002 Olympic games. Int J Sports Med. 2002;23:582-7.

38. Stewart AM, Hopkins WG. Consistency of swimming performance within and between competitions. Med Sci Sports Exerc. 2000;32:997-1001.

39. Neary JP, Bhambhani YN, McKenzie DC. Effects of different stepwise reduction taper protocols on cycling performance. Can J Appl Physiol. 2003; 28:576-87.

40. Halson SL, Bridge MW, Meeusen R, Busschaert B, Gleeson M, Jones DA. Time course of performance changes and fatigue markers during intensified training in trained cyclists. J Appl Physiol. 2002;93:947-56.

41. Issurin VB. Benefits and limitations of block periodized training approaches to Athletes' preparation: a review. Sports Med. 2016:46(3):329-38.

42. Hellard P, Scordia C, Avalos M, Mujika I, Pyne DB. Modelling of optimal training load patterns during the 11 weeks preceding major competition in elite swimmers. Appl Physiol Nutr Metab. 2017;42(10):1106-17.

43. Tønnessen E, Sylta Ø, Haugen TA, Hem E, Svendsen IS, Seiler S. The road to gold: training and peaking characteristics in the year prior to a gold medal endurance performance. PLoS One. 2014;9(7):e101796.

44. Kesäniemi A, Danforth E Jr, Jensen MD, et al. Dose-response issues concerning physical activity and health: an evidence-based symposium. Med Sci Sports Exerc. 2001:33:351-9.

45. Garber CE, Blissmer B, Deschenes MR, et al. American College of Sports Medicine position stand. Quantity and quality of exercise for developing and maintaining cardiorespiratory, musculoskeletal, and neuromotor fitness in apparently healthy adults: guidance for prescribing exercise. Med Sci Sports Exerc. 2011;43(7):1334-59.
46. Muñoz I, Varela-Sanz AV. Training intensity distribution and performance of a recreational male endurance runner. a case report. J Phys Educ Sport Manag. 2018;18(4):2257-63.

47. Lara B, Salinero JJ, Gallo-Salazar C, et al. Elevation of cardiac troponins after endurance running competitions. Circulation. 2019;139:709-11.

48. Buist I, Bredeweg SW, et al. Predictors of running-related injuries in novice runners enrolled in a systematic training program a prospective cohort study. Am J Sports Med. 2012;38(2):273-80.

49. Olson K, Zimka O, Pasiorowski A, et al. Tiredness, Fatigue, and Exhaustion as perceived by recreational marathon runners. Qual Heal Res. 2018;28:1997-2010.

50. Naclerio F, Moody J, Chapman MJ. Applied periodization: a methodological approach. Hum Sport Exerc. 2013;8(2):350-66

51. Zinner C, Schäfer Olstad D, Sperlich B. Different training intensity distribution in recreational runners. Med Sci Sports Exerc. 2018;50:1641-8.

52. Trappe S, Harber M, Creer A, Gallagher P, Slivka D, Minchev K, Whitsett D. Single muscle fiber adaptations with marathon training. J Appl Physiol (1985). 2006;101(3):721-7.

53. Carter JB, Banister EW, Blaber AP. The effect of age and gender on heart rate variability after endurance training. Med Sci Sports Exerc. 2003;35(8): $1333-40$.

54. Luden N, Hayes E, Minchev K. Skeletal muscle plasticity with marathon training in novice runners. Scand J Med Sci Sports. 2012;22(5):662-70.

55. Loimaala A, Huikuri H, Oja $\mathrm{P}$, et al. Controlled 5-mo aerobic training improves heart rate but not heart rate variability or baroreflex sensitivity. $J$ Appl Physiol (1985). 2000;89(5):1825-9.

56. Wolpern AE, Burgos DJ, Janot JM, et al. Is a threshold-based model a superior method to the relative percent concept for establishing individual exercise intensity? A randomized controlled trial. BMC Sports Sci Med Rehabil. 2015:4:7-16.

57. Costa P, Rhea M, Simão R, Leite T, Perez A, Palma A. Effects of Undulatory and non-Undulatory manipulations of aerobic workloads on aerobic performance. J Exerc Physiol Online. 2015;8:46-54.

58. Myers J, Prakash M, Froelicher $\mathrm{V}$, et al. Exercise capacity and mortality among men referred for exercise testing. N Engl J Med. 2002;346(11): 793-801.

59. Carnethon MR, Gulati M, Greenland P. Prevalence and cardiovascular disease correlates of low cardiorespiratory fitness in adolescents and adults. JAMA. 2005;294(23):2981-8

60. LaMonte MJ, Barlow CE, Jurca R, et al. Cardiorespiratory fitness is inversely associated with the incidence of metabolic syndrome: a prospective study of men and women. Circulation. 2005;112(4):505-12.

61. Sui X, LaMonte MJ, Laditka JN, et al. Cardiorespiratory fitness and adiposity as mortality predictors in older adults. JAMA. 2007;298(21):2507-16.

62. Arena R, Myers J, Williams MA, et al. Assessment of functional capacity in clinical and research settings: a scientific statement from the American Heart Association Committee on exercise, rehabilitation, and prevention of the council on clinical cardiology and the council on cardiovascular nursing Circulation. 2007;116(3):329-43.

63. Herdy AD, Caixeta A. Brazilian cardiorespiratory fitness classification based on maximum oxygen consumption. Arq Bras Cardiol. 2016;106(5):389-95.

64. American College of Sports Medicine. ACSM guidelines for exercise testing and prescripyion. 9th ed. Baltimore: Lippincott Williams\&Wilkins; 2013. p. 456

65. Lohman TG. Body composition methodology in sports medicine. Phys Sportsmed. 1982;10(12):46-7.

66. Blair SN, Chandler JV, Ellisor DB, Langley T. Improving physical fitness by exercise training programs. South Med J. 1980;73:1594-6.

67. Gaesser GA, Rich RG. Effects of high- and low-intensity exercise training on aerobic capacity and blood lipids. Med Sci Sports Exerc. 1984;16:269-74.

68. Hagberg JM, Graves JE, LIMACHER M, et al. Cardiovascular responses of 70- to 79-yr-old men and women to exercise training. J Appl Physiol. 1989;66:2589-94.

69. Suter E, Marti B, Gutzwiller F. Jogging or walking: comparison of health effects. Ann Epidemiol. 1994;4:375-81.

70. Carnes AJ, Mahoney SE. Polarized vs. high intensity multimodal training in recreational runners. Int J Sports Physiol Perform. 2018;28:1-28.

71. Office of Disease Prevention and Health Promotion. US Department of Health and Human Services. Healthy People 2020: Topics \& ObjectivesPhysical Activity. https://www.healthypeople.gov/2020/topics-objectives/ topic/physical-activity. Accessed 15 Nov 2018 
72. Siri WE. Body composition from fluid spaces and density: analysis of methods. 1961. Nutrition. 1993;9:480-91.

73. Jackson AS, Pollock ML. Generalized equations for prediting body density of men. Br J Nutr. 1978:40:497-504.

74. Garcia-Tabar I, Eclache JP, Aramendi JF, et al. Gas analyzer's drift leads to systematic error in maximal oxygen uptake and maximal respiratory exchange ratio determination. Front Physiol. 2015;30(6):308.

75. Edvardsen $\mathrm{E}$, Scient $\mathrm{C}$, Hansen $\mathrm{BH}$, et al. Reference values for cardiorespiratory response and fitness on the treadmill in a 20- to 85- yearold population. Chest. 2013;144(1):241-8.

76. Tanaka H, Monahan KD, Seals DR. Age - predicted maximal heart revisited. J Am Coll Cardiol. 2001;37:153-6.

77. Bruce RA, Kusumi F, Hosmer D. Maximal oxygen uptake and nomographic assessment of functional aerobic capacity impairment in cardiovascular disease. Am Heart J. 1973:85:546-62.

78. Cohen D. Statistical power analysis for the behavioral sciences. Hillsdale: Lawrence Erlbaum Associates, Publisher; 1988. p. 567.

79. Buchheit $M$, Chivot A, Parouty J, et al. Monitoring endurance running performance using cardiac parasympathetic function. Eur J Appl Physiol. 2010;108(6):1153-67.

80. Hautala AJ, Makikallio TH, Kiviniemi A, et al. Cardiovascular autonomic function correlates with the response to aerobic training in healthy sedentary subjects. Am J Physiol Heart Circ Physiol. 2003;285:H1747-52.

81. Katch V, Weltman A, Sady S, et al. Validity of the relative percent concept for equating training intensity. Eur J Appl Physiol Occup Physiol. 1978;39(4):219-27.

82. Pollock ML. The quantification of endurance training programs. In: Wilmore JA, editor. Exercise and sport science reviews. New York: Academic; 1973. p. 155-88.

83. Mann TN, Lamberts RP, Lambert MI. High responders and low responders: factors associated with individual variation in response to standardized training. Sports Med. 2014:44:1113-24.

84. Schumacher YO, Jankovits R, Bültermann D, Schmid A, Berg A. Hematological indices in elite cyclists. Scand J Med Sci Sports. 2002; 12(5):301-8

85. Mujika I, Padilla S, Geyssant A. Hematological responses to training and taper in competitive swimmers: relationships with performance. Arch Physiol Biochem. 1997;105:379-85.

86. Santhiago V, Da Silva ASR, Papoti M. Responses of hematological parameters and aerobic performance of elite men and women swimmers during a 14-week training program. J Strength Cond Res. 2009;23:1097-105.

87. Convertino VA. Blood volume: its adaptation to endurance training. Med Sci Sports Exerc. 1991;23(12):1338-48.

88. Kirwan JP, Costill DL, Flynn MG, Mitchell JB, Fink WJ, Neufer PD, Houmard JA. Physiological responses to successive days of intense training in competitive swimmers. Med Sci Sports Exerc. 1988;20:255-9.

89. Thirup P. Haematocrit: within-subjected and seasonal variation. Sports Med. 2003:33:231-43.

90. Schumacher YO, Schmid A, Grathwohl D, Bultermann D, Berg A Hematological indices and iron status in athletes of various sports and performances. Med Sci Sports Exerc. 2002;34:869-75.

91. Casoni I, Borsetto C, Cavicchi A, Martinelli S, Conconi F. Reduced hemoglobin concentration and red cell hemoglobinization in Italian marathon and ultramarathon runners. Int J Sports Med. 1985;6(3):176-9.

92. Irving BA, Davis CK, Brock DW, Weltman JY, Swift D, Barrett EJ, Gaesser G, Weltmlan A. Effect of exercise training intensity on abdominal visceral fat and body composition. Med Sci Sports Exerc. 2008;40(11):1863-72.

93. Hottenrott K, Ludyga S, Schulze S. Effects of high intensity training and continuous endurance training on aerobic capacity and body composition in recreationally active runners. J Sports Sci Med. 2012;11(3):483-8.

94. Mondal H, Mishra SP. Effect of BMI, Body Fat Percentage and Fat Free Mass on Maximal Oxygen Consumption in Healthy Young Adults. J Clin Diagn Res 2017;11(6):CC17-CC20.

95. Mazić S, Lazović B, Delić M, Lazić JS, Aćimović T, Brkić P. Body composition assessment in athletes: a systematic review. Med Pregl. 2014;67(7-8):255-60.

96. Clarkson PM, Hubal MJ. Exercise-induce muscle damage in humans. Am J Phys Rehabil. 2002;81:S52-69.

97. Davies RC, Eston RG, Poole DC, Rowlands AV, DiMenna F, Wilkerson DP, Twist $C$, Jones AM. Effect of eccentric exercise induced muscle damage on the dynamics of muscle oxygenation and pulmonary oxygen uptake. J Appl Physiol. 2008;105(5):1413-21.
98. Shaskey DJ, Green GA. Sports haematology. Sports Med. 2000;29:27Y38.

99. Friden J, Lieber RL. Segmental muscle fiber lesions after repetitive eccentric contractions. Cell Tissue Res. 1998;293:165-71.

100. Lieber RL, Shah S, Fridén J. Cytoskeletal disruption after eccentric contraction-induced muscle injury. Clin Orthop. 2002;403:S90-9.

101. Hortobagyi T, Denahan T. Variability in creatine kinase: methodological, exercise and clinically related factors. Int J Sports Med. 1989;10:69-80.

102. Brancaccio P, Maffulli N, Limongelli FM. Creatine kinase monitoring in sport medicine. Br Med Bull. 2007;81-82:209-30.

103. Wiewelhove T, Schneider C, Döweling A, Hanakam F, Rasche C, Meyer T, Kellmann M, Pfeiffer M, Ferrauti A. Effects of different recovery strategies following a half-marathon on fatigue markers in recreational runners. PLoS One. 2018;13(11).

104. Mujika I, Padilla S, Pyne D, Busso T. Physiological changes associated with the pre-event taper in athletes. Sports Med. 2004;34(13):891-927.

105. Child RB, Wilkinson DM, Fallowfield JL. Effects of a training taper on tissue damage indices, serum antioxidant capacity and half-Marathon running performance. Int J Sports Med. 2000;21:325-31.

106. Flynn MG, Pizza FX, Boone JB Jr, Andress FF, Michaud TS, Rodriguez-Zavas JR. Indices of training stress during competitive running and swimming seasons. Int J Sports Med. 1994;15:21-6.

107. Skenderi KP, Kavouras SA, Anastasiou CA, Yiannakouris N, Matalas AL. Exertional rhabdomyolysis during a 246-km continuous running race. Med Sci Sports Exerc. 2006;38(6):1054-7.

108. Son HJ, Lee $\mathrm{YH}$, Chae JH, Kim CK. Creatine kinase isoenzyme activity during and after an ultra-distance (200 km) run. Biol Sport. 2015;32(4):357-61.

109. Lippi G, Schena F, Montagnana M, Salvagno GL, Banfi G, Guidi GC. Significant variation of traditional markers of liver injury after a halfmarathon run. Eur J Intern Med. 2011;22(5):e36-8.

110. Oosthuyse T, Avidon I. Changes in substrate utilisation and protein catabolism during multiday cycling in well-trained cyclists. J Sports Sci. 2015;33(5):507-17.

111. Kargotich S, Keast D, Goodman C, Bhagat Cl, Joske DJ, Dawson B, Morton AR. Monitoring 6 weeks of progressive endurance training with plasma glutamine. Int J Sports Med. 2007;28(3):211-6.

112. Sjödin B, Hellsten WY. Changes in plasma concentration of hypoxanthine and uric acid in man with short-distance running at various intensities. Int J Sports Med. 1990;11:493-5.

113. de Araujo GG, Papoti M, Dos Reis IG, de Mello MA, Gobatto CA. Short and long term effects of high-intensity interval training on hormones, metabolites, antioxidant system, glycogen concentration, and aerobic performance adaptations in rats. Front Physiol. 2016;7:505.

114. Janssen GM, Degenaar CP, Menheere PP, et al. Plasma urea, creatinine, uric acid, albumin, and total protein concentrations before and after 15-, 25-, and 42-km contests. Int J Sports Med. 1989;10(suppl 3):S132-8.

115. Refsum HE, Tveit B, Meen HD, et al. Serum electrolyte, fluid and acid-base balance after prolonged heavy exercise at low environmental temperature. Scand J Clin Lab Invest. 1973;32:117-22.

116. Leers MP, Schepers R, Baumgarten R. Effects of a long distance run on cardiac markers in healthy athletes. Clin Chem Lab Med. 2006;44:999-1003.

117. Costill DL, Thomas R, Robergs A, et al. Adaptations to swimming training: influence of training volume. Med Sci Sports Exerc. 1991;23:371-7.

118. Bonifazi M, Sardella F, Luppo C. Preparatory versus main competitions: differences in performances, lactate responses and pre-competition plasma cortisol concentrations in elite male swimmers. Eur J Appl Physiol. 2000;82:368-73.

119. Steinacker JM, Lormes W, Kellmann M, et al. Training of junior rowers before world championships: effects on performance, mood state and selected hormonal and metabolic responses. J Sports Med Phys Fitness. 2000;40:327-35.

120. Martin DT, Andersen MB. Heart rate-perceived exertion relationship during training and taper. J Sports Med Phys Fitness. 2000;40:201-8.

121. Goldspink G. Cellular and molecular aspects of adaptation in skeletal muscle. In: Komi PV, editor. Strength and power in sport. Oxford: Blackwell Scientific Publications; 1992. p. 221-9.

122. Galbo H. Influence of aging and exercise on endocrine function. Int J Sport Nutr Exerc Metab. 2001;11:49-57.

123. Dressendorfer $\mathrm{RH}$, Petersen SR, Moss Lovshin SE, et al. Performance enhancement with maintenance of resting immune status after intensified cycle training. Clin J Sport Med. 2002;12(5):301-7.

124. Gastmann U, Dimeo F, Huonker M, et al. Ultra-triathlon-related bloodchemical and endocrinological responses in nine athletes. J Sports Med Phys Fitness. 1998;38(1):18-23. 
125. Keizer HA. Neuroendocrine aspects of overtraining. In: Kreider RB, Fry AC, OToole ML, editors. Overtraining in sport. Champaign: Human Kinetics; 1998. p. 145-67.

Submit your manuscript to a SpringerOpen ${ }^{\mathcal{O}}$ journal and benefit from:

- Convenient online submission

- Rigorous peer review

- Open access: articles freely available online

- High visibility within the field

- Retaining the copyright to your article

Submit your next manuscript at $\boldsymbol{\nabla}$ springeropen.com 